CENTRE for ECONOMIC

$P$ E R F O R M A N C E

CEP Discussion Paper No 677

February 2005

\title{
Evaluating the Performance of the \\ Search and Matching Model
}

\author{
Eran Yashiv
}

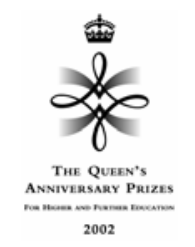




\begin{abstract}
Does the search and matching model fit aggregate U.S. labor market data? While the model has become an important tool of macroeconomic analysis, recent literature pointed to some failures in accounting for the data. This paper aims to answer two questions: (i) Does the model fit the data, and, if so, on what dimensions? (ii) Does the data "fit" the model, i.e. what are the data which are relevant to be explained by the model? The analysis shows that the model does fit certain specifications of the data on many dimensions, though not on all. This includes capturing the high persistence and high volatility of most of the key variables, as well as the negative co-variation of unemployment and vacancies. It offers a workable, empirically-grounded version of the model for the analysis of aggregate U.S. labor market dynamics. The paper provides macroeconomists guidance concerning the relevant "building block" for modelling the labor market, both in terms of the model and in terms of the data.
\end{abstract}

JEL codes: E24, E32, J32, J63

Key words: search, matching, U.S. labor market, vacancies, labor market flows, business cycles.

This paper was produced as part of the Centre's Technology and Growth Programme. The Centre for Economic Performance is financed by the Economic and Social Research Council.

\title{
Acknowledgements
}

Eran Yashiv is an associate of the Centre for Economic Performance, and Visiting Reader in the Economics Department, London School of Economics.

Contact E-mail: yashiv@post.tau.ac.il; e.yashiv@1se.ac.uk.

Published by

Centre for Economic Performance

London School of Economics and Political Science

Houghton Street

London WC2A 2AE

All rights reserved. No part of this publication may be reproduced, stored in a retrieval system or transmitted in any form or by any means without the prior permission in writing of the publisher nor be issued to the public or circulated in any form other than that in which it is published.

Requests for permission to reproduce any article or part of the Working Paper should be sent to the editor at the above address.

(C) E. Yashiv, submitted 2005

ISBN 0753018179 


\section{Introduction}

The importance of the role played by labor market frictions in labor market dynamics and in macroeconomic fluctuations is increasingly recognized. The key modelling tool in this context is the aggregate search and matching model developed by Diamond, Mortensen and Pissarides [see Mortensen and Pissarides (1999 a,b) for surveys and Pissarides (2000) for a detailed exposition]. However, recent papers have questioned the model's empirical performance in U.S. data. This literature poses doubts with respect to the model's ability to account for the observed behavior of key variables - unemployment, vacancies, worker flows, wages, and the duration of unemployment. The aims of this paper are to answer two questions: (i) Does the model fit the data, and, if so, on what dimensions? (ii) Does the data "fit" the model, i.e. which data are relevant in the context of the model? The analysis produces a workable, empirically-grounded version of the model that may be used to analyze U.S. data and study policy questions. The basic motivation is to try to understand whether the model - beyond its theoretical appeal - is indeed useful for the analysis of the U.S. labor market. The idea is to make precise the dimensions on which the model does well and those on which it does not do well or even fails.

When coming to undertake such analysis a number of fundamental problems arise:

(i) How to model the driving shocks? It is known from the business cycle literature that fluctuations often mimic the pattern of the shocks and that the model itself may lack propagation mechanisms. A similar problem may be the case here too.

(ii) How to avoid the "contamination" of labor market analysis by mis-specification of other parts of the macroeconomy? General equilibrium models have well-known problems that are yet to

\footnotetext{
${ }^{1}$ Prepared for the conference in honor of Dale Mortensen at Sandbjerg, Denmark, August 15-18, 2004. I am indebted to Dale for inspiration and encouragement over the years. I am grateful to Jordi Gali, Martin Lettau, Fabien Postel-Vinay and Etienne Wasmer for useful conversations, to Craig Burnside for advice, data and software, to Jeffrey Fuhrer, Hoyt Bleakley, Ann Ferris and Elizabeth Walat for data, and to Darina Waisman for excellent research assistance. Any errors are mine.
} 
be resolved. Studying the empirical performance of the search and matching model in conjunction with other parts of the macroeconomy could thus lead to rejection of the model due to the aforementioned "contamination."

(iii) How to model the frictions so as to determine what role they play in explaining the data? Many studies in the literature are highly stylized, use short cuts, or employ reduced-form modelling that is useful for theoretical exposition but is problematic when attempting an empirical examination of the model. It is then difficult to see how the degree of frictions matters in accounting for the data. For a model that puts frictions at center stage this is highly problematic. Thus, in cases where the model is shown not to fit the data, it is not always clear whether a particular specification of labor market frictions is responsible for the difficulty or whether this reflects a more essential problem.

(iv) How to determine the equilibrium effects of shocks? There is a need for a structural model that can trace out the effects of shocks on equilibrium dynamics and determine what is the role of frictions in this process.

(v) What are the proper data to use for the key elements of the model - the pool of searching workers and the stock of searching jobs (vacancies)? Questions regarding these data have been raised a number of times by different authors but have not been systematically treated in the current context. Hence, it is unclear to which extent the model-data fit is subject to problems with the data used rather than to problems with the model.

The paper takes the following approach to address these problems: to deal with (i) and (ii), it uses a partial equilibrium model and a reduced-form VAR of the actual data to specify the driving shocks. This 'agnostic' approach precludes the possibility that labor market dynamics will be affected by misspecifications in other parts of a more general macroeconomic model. Thus it does not take a particular stand on the sources of the driving shock processes nor does it formulate an explicit structure for the rest of the macroeconomy. To deal with (iii) and (iv) it uses a structural approach: it specifies agents' objectives and constraints, their optimal behavior, and the dynamic paths of key variables in equilibrium. The structural parameters quantify the degree of frictions. The fifth issue is treated by looking at alternative formulations of the pool of searching workers, taking into account also non-employed workers outside the official unemployment pool. The paper 
also uses newly available gross worker flows data that are compatible with the model's formulations, rather than vacancy data, which are shown to be inconsistent with the concepts of the model.

The model is a stochastic version of the search and matching model. It characterizes firms' optimal search behavior, deriving a relationship that equates marginal hiring costs with the present value of a hire - the "asset value" of the job-worker match. The firm's decision on vacancy creation feeds into a matching function, which generates a flow of hires given the stocks of job vacancies and unemployment. The wage is determined by the Nash bargaining solution, which splits the surplus from the job-worker match. The resulting model is a partial equilibrium model, with employment (and unemployment), vacancies, and the wage defined by the equilibrium solution.

The non-linear equilibrium solution of the model is log-linearized using a first-order Taylor approximation to obtain a system of linear difference equations. The system formalizes the dynamics of the key variables in terms of exogenous, stochastic variables and in terms of structural parameters that quantify the frictions. The model is then calibrated. As mentioned, a reduced-form VAR determines the relevant parameters for the exogenous shock processes. These include labor productivity shocks, shocks to the match separation rate, and shocks to the discount rate. Other calibrated values are set using historical data averages or econometric estimates. The model's implied second moments are compared to U.S. data in terms of persistence, co-movement, and volatility.

I find that for the most part the model fits U.S. labor market data relatively well. This includes capturing the high persistence and high volatility of most of the key variables, as well as the negative co-variation of unemployment and vacancies (the 'Beveridge curve').

The paper makes several contributions: first, it offers an empirically-grounded model of aggregate U.S. labor market dynamics as implied by the search and matching model. Doing so it provides macroeconomists some guidance concerning the relevant "building block" for modelling the labor market. Second, by calibrating the model and evaluating it against alternative formulations of the data, it is able to show on what dimensions the model fits the data and which data series are the relevant ones. Third, particular specifications of the model are able to replicate key empirical regularities in U.S. data which other models have been unable to capture; the reasons for this improved performance are discussed. In terms of the calibration-simulation methodology, there is 
an innovation in the "agnostic" approach taken with respect to the formulation of shocks.

The paper proceeds as follows: Section 2 presents the search and matching model. At the end of this section I point out the contributions of Dale Mortensen in the current, macroeconomic context. Section 3 derives the equilibrium dynamics and steady state, highlighting the role of frictions. Section 4 discusses the data series, presents the properties of the data that are to be matched, and proposes alternative formulations of the data to be used. It also reports the results from recent literature that found problems in the fit of the model. Section 5 calibrates the model and evaluates the model-data fit. Section 6 examines the mechanism underlying the results, deriving the modelling and data lessons for using the model to study the U.S. labor market. Section 7 concludes.

\section{The Search and Matching Model}

In this section I briefly present a stochastic, discrete-time version of the prototypical search and matching model. ${ }^{2}$ An important addition to the standard analysis is a convex formulation for the hiring costs function, which has the standard linear formulation as a special case. This in turn necessitates taking into account the effect of employment on wages in the firm's optimality condition and in the wage solution.

\subsection{The Basic Set-Up}

There are two types of agents: unemployed workers $(U)$ searching for jobs and firms recruiting workers through vacancy creation $(V)$. Firms maximize their intertemporal profit functions with the choice variable being the number of vacancies to open. Each firm produces a flow of output $(F)$, paying workers wages $(W)$ and incurring hiring costs $(\Gamma)$. Workers and firms are faced with different frictions such as different locations leading to regional mismatch or lags and asymmetries in the transmission of information. These frictions are embedded in the concept of a matching function which produces hires $(M)$ out of vacancies and unemployment, leaving certain jobs unfilled and certain workers unemployed. Workers are assumed to be separated from jobs at a stochastic,

\footnotetext{
${ }^{2} \mathrm{~A}$ detailed exposition may be found in Pissarides (2000). The stochastic, discrete time formulation presented here follows Yashiv (2004).
} 
exogenous rate, to be denoted by $\delta$. The labor force $(L)$ is growing with new workers flowing into the unemployment pool. The set-up, whereby search is costly and matching is time-consuming, essentially describes the market as one with trade frictions. Supply and demand are not equilibrated instantaneously, so at each date $t$ there are stocks of unemployed workers and vacant jobs.

The model assumes a market populated by many identical workers and firms. Hence I shall continue the discussion in terms of "representative agents." Each agent is small enough so that the behavior of other agents is taken as given. As is well known this creates various externalities. In particular, more search activity creates a positive trading externality for the trading partner and a congestion externality for similar agents [see the discussion in Pissarides (2000, chapter 7)].

\subsection{Matching}

A matching function captures the frictions in the matching process; it satisfies the following properties

$$
\begin{aligned}
M_{t, t+1} & =\widetilde{M}\left(U_{t}, V_{t}\right) \\
\frac{\partial \widetilde{M}}{\partial U} & >0, \frac{\partial \widetilde{M}}{\partial V}>0
\end{aligned}
$$

Empirical work [see the survey by Petrongolo and Pissarides (2001)] has shown that a Cobb-Douglas function is useful for parameterizing it:

$$
M_{t, t+1}=\mu U_{t}^{\sigma} V_{t}^{1-\sigma}
$$

where $\mu$ stands for matching technology. From this function the hazard rates $-P$, the worker probability of finding a job and $Q$, the firm's probability of filling the vacancy - are derived:

$$
\begin{aligned}
P_{t, t+1} & =\frac{M_{t, t+1}}{U_{t}}=\mu\left(\frac{V_{t}}{U_{t}}\right)^{1-\sigma} \\
Q_{t, t+1} & =\frac{M_{t, t+1}}{V_{t}}=\mu\left(\frac{V_{t}}{U_{t}}\right)^{-\sigma}
\end{aligned}
$$

The parameter $\sigma$ reflects the relative contribution of unemployment to the matching process and determines the elasticity of the hazard rates with respect to market tightness. 


\subsection{Firms}

Firms maximize the expected, present value of profits (where all other factors of production have been "maximized out"):

$$
\max _{\{V\}} E_{0} \sum_{t=0}^{\infty}\left(\prod_{j=0}^{t} \beta_{j}\right)\left[F_{t}-W_{t} N_{t}-\Gamma_{t}\right]
$$

where $\beta_{j}=\frac{1}{1+r_{t-1, t}}$.

This maximization is done subject to the employment dynamics equation given by:

$$
N_{t+1}=\left(1-\delta_{t, t+1}\right) N_{t}+Q_{t, t+1} V_{t}
$$

The Lagrangean of this problem is (where $\Lambda$ is the discounted Lagrange multiplier):

$$
\mathfrak{L}=E_{0} \sum_{t=0}^{\infty}\left(\prod_{j=0}^{t} \beta_{j}\right)\left[F_{t}-W_{t} N_{t}-\Gamma_{t}+\Lambda_{t}\left\{\left(1-\delta_{t, t+1}\right) N_{t}+Q_{t, t+1} V_{t}-N_{t+1}\right\}\right]
$$

The F.O.C are:

$$
\begin{gathered}
\frac{\partial \Gamma_{t}}{\partial V_{t}}=Q_{t, t+1} E_{t} \Lambda_{t} \\
\Lambda_{t}=E_{t} \beta_{t+1}\left[\frac{\partial F_{t+1}}{\partial N_{t+1}}-\frac{\partial \Gamma_{t+1}}{\partial N_{t+1}}-W_{t+1}-N_{t+1} \frac{\partial W_{t+1}}{\partial N_{t+1}}\right]+E_{t}\left(1-\delta_{t+1, t+2}\right) \beta_{t+1} \Lambda_{t+1} \\
N_{t+1}=\left(1-\delta_{t, t+1}\right) N_{t}+Q_{t, t+1} V_{t}
\end{gathered}
$$

and the transversality condition:

$$
\lim _{T \rightarrow \infty} E_{t}\left[\left(\prod_{j=0}^{T-1} \beta_{j}\right)\left\{\frac{\partial F_{T}}{\partial N_{T}}-W_{T}-\frac{\frac{\partial \Gamma_{T-1}}{\partial N_{T-1}}}{\beta_{T-1}}-N_{T-1} \frac{\partial W_{T-1}}{\partial N_{T-1}}\right\} N_{T}\right]=0
$$

The first, intratemporal condition (equation 8) sets the marginal cost of hiring $\frac{\partial \Gamma_{t}}{\partial V_{t}}$ equal to the expected value of the multiplier times the probability of filling the vacancy. The second, intertemporal condition (equation 9) sets the multiplier equal to the sum of the expected, discounted 
marginal profit in the next period $E_{t} \beta_{t+1}\left[\frac{\partial F_{t+1}}{\partial N_{t+1}}-W_{t+1}-\frac{\partial \Gamma_{t+1}}{\partial N_{t+1}}-N_{t+1} \frac{\partial W_{t+1}}{\partial N_{t+1}}\right]$ and the expected, discounted (using also $\delta$ ) value of the multiplier in the next period $E_{t}\left(1-\delta_{t+1, t+2}\right) \beta_{t+1} \Lambda_{t+1}$. Note that because I postulate that $\Gamma$ depends on $N$ (see below), the net marginal product for the firm depends on $N$. This marginal product is part of the match surplus bargained over, and therefore part of the wage solution discussed below. Hence the term $\frac{\partial W_{t+1}}{\partial N_{t+1}}$, usually absent, is not zero in this formulation.

For production I assume a standard Cobb-Douglas function:

$$
F_{t}=A_{t} K_{t}^{\alpha} N_{t}^{1-\alpha}
$$

where $A$ is technology and $K$ is capital.

Hiring costs refer to the costs incurred in all stages of recruiting: the cost of advertising and screening - pertaining to all vacancies $(V)$, and the cost of training and disrupting production pertaining to actual hires $(Q V)$. For the functional form I use a general power function formulation which encompasses the widely-used linear and quadratic functions as special cases. This functional form emerged as the preferred one - for example as performing better than polynomials of various degrees - in structural estimation of this model reported in Yashiv (2000a,b) and in Merz and Yashiv (2004). The former study used an Israeli data-set that is uniquely suited for such estimation with a directly measured vacancy series that fits well the model's definitions. The latter study used U.S. data. Formally this function is given by:

$$
\Gamma_{t}=\frac{\Theta}{1+\gamma}\left(\frac{\phi V_{t}+(1-\phi) Q_{t} V_{t}}{N_{t}}\right)^{\gamma+1} F_{t}
$$

Hiring costs are function of the weighted average of the number of vacancies and the number of hires. They are internal to production and hence are proportional to output. The function is linearly homogenous in $V, N$ and $F$. It encompasses the cases of a fixed cost per vacancy (i.e. linear costs, $\gamma=0)$ and increasing costs $(\gamma>0)$. When $\gamma=1$ I get the quadratic formulation $\left(\frac{\Theta}{2}\left(\frac{\phi V_{t}+(1-\phi) Q_{t} V_{t}}{N_{t}}\right)^{2} F_{t}\right)$ which is analogous to the standard formulation in "Tobin's q" models of investment where costs are quadratic in $\frac{I}{K}$. Note that $\Theta$ is a scale parameter, $\phi$ is the weight given to vacancies as distinct from actual hires, and $\gamma$ expresses the degree of convexity. ${ }^{3}$

\footnotetext{
${ }^{3}$ Note that its derivatives, used below, are given by:
} 


\subsection{Wages}

In this model, the matching of a worker and a vacancy against the backdrop of search costs, creates a joint surplus relative to the alternatives of continued search. Following Diamond (1982) and Mortensen (1982), the prototypical search and matching model derives the wage $(W)$ as the Nash solution of the bargaining problem of dividing this surplus between the firm and the worker [see the discussion in Pissarides (2000, Chapters 1 and 3)].

Formally this wage is:

$$
W_{t}=\arg \max \left(J_{t}^{N}-J_{t}^{U}\right)^{\xi}\left(J_{t}^{F}-J_{t}^{V}\right)^{1-\xi}
$$

where $J^{N}$ and $J^{U}$ are the present value for the worker of employment and unemployment respectively; $J^{F}$ and $J^{V}$ are the firm's present value of profits from a filled job and from a vacancy respectively; and $0<\xi<1$ reflects the degree of asymmetry in bargaining.

Using the Stole and Zweibel (1996) approach as implemented by Cahuc, Marque and Wasmer (2004) to solve (14) taking into account the fact that $\frac{\partial W_{t+1}}{\partial N_{t+1}} \neq 0$, the wage is given by: ${ }^{4}$

$$
\begin{aligned}
W_{t}= & \xi\left(\begin{array}{c}
(1-\alpha) A\left(\frac{K_{t}}{N_{t}}\right)^{\alpha}\left[\frac{1}{1-\alpha \xi}+\Theta\left(\frac{\phi V_{t}+(1-\phi) Q_{t} V_{t}}{N_{t}}\right)^{\gamma+1} \frac{\alpha+\gamma}{(1+\gamma)(1-\alpha)(1-\xi(1+\alpha+\gamma))}\right] \\
+P_{t, t+1} \Lambda_{t}
\end{array}\right) \\
& +(1-\xi) b_{t}
\end{aligned}
$$

where $b$ is the income of the unemployed, such as unemployment benefits.

I assume that $b_{t}$ is proportional to $W_{t}$ i.e. $b_{t}=\tau W_{t}$, so $\tau$ may be labelled the "replacement ratio." Hence:

$$
\begin{aligned}
\frac{\partial \Gamma_{t}}{\partial V_{t}} & =\Theta\left(\phi+(1-\phi) Q_{t}\right)\left(\frac{\phi V_{t}+(1-\phi) Q_{t} V_{t}}{N_{t}}\right)^{\gamma} \frac{F_{t}}{N_{t}} \\
\frac{\partial \Gamma_{t}}{\partial N_{t}} & =\Theta\left(\frac{\phi V_{t}+(1-\phi) Q_{t} V_{t}}{N_{t}}\right)^{\gamma+1} \frac{F_{t}}{N_{t}}\left[\frac{1-\alpha}{1+\gamma}-1\right]
\end{aligned}
$$

${ }^{4}$ The solution entails postulating the asset values of a filled job and of a vacant job for the firm and the asset values of employment and unemployment for the worker in (14). See the technical appendix at http://www.tau.ac.il/ yashiv/performance.html for details of the derivation. 


$$
W_{t}=\frac{\xi}{1-(1-\xi) \tau}\left(\begin{array}{c}
\left.(1-\alpha) A\left(\frac{K_{t}}{N_{t}}\right)^{\alpha}\left[\frac{1}{1-\alpha \xi}+\Theta\left(\frac{\phi V_{t}+(1-\phi) Q_{t} V_{t}}{N_{t}}\right)^{\gamma+1} \frac{\alpha+\gamma}{(1+\gamma)(1-\alpha)(1-\xi(1+\alpha+\gamma))}\right]\right) \\
+P_{t, t+1} \Lambda_{t}
\end{array}\right)
$$

Denoting $\frac{\xi}{1-(1-\xi) \tau}$ by $\eta$ and formulating the wage in terms of the labor share in income (by dividing this wage by the average product) I get:

$$
\begin{aligned}
W_{t} & =s_{t} \frac{F_{t}}{N_{t}} \\
s_{t} & =\eta\left(\begin{array}{c}
\left.(1-\alpha)\left[\frac{1}{1-\alpha \xi}+\Theta\left(\frac{\phi V_{t}+(1-\phi) Q_{t} V_{t}}{N_{t}}\right)^{\gamma+1} \frac{\alpha+\gamma}{(1+\gamma)(1-\alpha)(1-\xi(1+\alpha+\gamma))}\right]\right) \\
+P_{t, t+1} \lambda_{t}
\end{array}\right)
\end{aligned}
$$

This wage solution has the following properties:

a. Wages are proportional to productivity $\frac{F_{t}}{N_{t}}$ but the proportionality coefficient $s_{t}$ is timevarying.

b. Wages and the wage share increase with worker bargaining power $(\xi)$ or replacement ratio $(\tau)$ as expressed by $\eta$.

c. Wages and the wage share are a positive function of the future value given by $P_{t, t+1} \lambda_{t}$. Thus wages are positively related to the asset value of the match.

\subsection{Equilibrium}

The stocks of unemployment and employment and the flow of hiring emerge as equilibrium solutions. Solving the firms' maximization problem yields a dynamic path for vacancies; these and the stock of unemployment serve as inputs to the matching function; matches together with separation rates and labor force growth change the stocks of employment and unemployment. Formally: 


$$
\begin{aligned}
V_{t} & =\arg \max E_{0} \sum_{t=0}^{\infty}\left(\prod_{j=0}^{t} \beta_{j}\right)\left[F_{t}-W_{t} N_{t}-\Gamma_{t}+\Lambda_{t}\left\{\left(1-\delta_{t, t+1}\right) N_{t}+Q_{t, t+1} V_{t}-N_{t+1}\right\}\right] \\
U_{t} & =L_{t}-N_{t} \\
M_{t, t+1} & =\widetilde{M}\left(U_{t}, V_{t}\right) \\
N_{t+1} & =\left(1-\delta_{t, t+1}\right) N_{t}+M_{t, t+1} \\
W_{t} & =\arg \max \left(J_{t}^{N}-J_{t}^{U}\right)^{\xi}\left(J_{t}^{F}-J_{t}^{V}\right)^{1-\xi}
\end{aligned}
$$

This dynamic system may be solved for the five endogenous variables $V, U, M, N$ and $W$ given initial values $U_{0}, N_{0}$ and given the path of the exogenous variables. The latter include $\beta, \delta$ and $L$, variables included in the firms' profit function and variables included in the workers unemployment value function $J^{U}$.

As noted above, this is a partial equilibrium model. The exogenous variables include the worker's marginal product, the discount factor and the separation rate. If the production function is CRS and if the capital market is perfect - as I shall assume - the capital-labor ratio will be determined in equilibrium at the point where the marginal product of capital equals the interest rate plus the rate of depreciation. This in turn will determine production and the marginal product of labor. This set-up is consistent with several different macroeconomic models. For example Merz (1995) and Andolfatto (1996) have shown that a special case of this model may be combined with traditional elements of RBC models to yield a dynamic general equilibrium model. In these models the interest rate equals the marginal rate of intertemporal substitution in consumption.

In the following section I solve explicitly for a stochastic, dynamic equilibrium using a stochastic structure for the exogenous variables.

\subsection{The Contributions of Dale Mortensen}

Dale Mortensen has made fundamental contributions to the model presented above. The first one, in the celebrated 1970 "Phelps volume" [Mortensen (1970)], introduced the flow approach to the labor market and incorporated search costs. In that paper the firm's intertemporal choice was shown to be akin to investment with adjustment costs. The papers which followed introduced all the key ingredients of the model: bilateral matching and surplus division in Mortensen (1978), 
aggregate matching and surplus division using the Nash solution in Mortensen (1982a); the last paper also discussed the incentives of agents to engage in search. Efficiency aspects of the matching and bargaining situations were analyzed in Mortensen (1982b). Finally the model was expanded to incorporate idiosyncratic productivity and endogenous separations in Mortensen and Pissarides (1994).

\section{Steady State and the Stochastic Dynamic Equilibrium}

I use a log-linear approach, transforming the non-linear problem into a first-order, linear, difference equations system through approximation and then solving the system using standard methods. More specifically I undertake the following steps:

(i) I postulate a stochastic set-up for the exogenous variables. As noted in the introduction, I use a reduced-form VAR procedure to characterize the shocks rather than imposing a structural formulation.

(ii) Using the F.O.C, I characterize the non-stochastic steady state.

(iii) The deterministic version of the F.O.C of the firm's problem, including the flow equation for employment, is linearly approximated in the neighborhood of this steady state, using a firstorder Taylor approximation.

(iv) This yields a first-order, linear, difference equations system, which solution gives the dynamic path of the control and the endogenous state variables as functions of sequences of the exogenous variables.

(v) Working from a certainty equivalence perspective, the deterministic sequences for the exogenous variables are then replaced with the conditional expectations at time $t$ for the afore-cited stochastic processes.

\subsection{Dynamic Solution}

Basically I am interested in exploring the dynamics of the labor market relative to its growth trend. Growth comes from two sources: productivity growth and population growth. To abstract from population growth, in what follows I cast all labor market variables in terms of rates out of the labor 
force $L_{t}$, denoting them by lower case letters. Productivity growth is captured by the evolution of $A$, which enters the model through the dynamics of $\frac{F_{t}}{N_{t}}$ so I divide all variables by the latter. This leaves a system that is stationary and is affected by shocks to labor force growth, to productivity growth, as well as to the interest rate and to the job separation rate, to be formalized below.

I now further develop the F.O.C. in order to get a stationary representation with fewer variables. I begin with (8). Transforming the equation into a stationary one through the aforementioned divisions the equation becomes:

$$
\Theta\left(\phi+(1-\phi) Q_{t}\right)\left(\frac{\phi V_{t}+(1-\phi) Q_{t} V_{t}}{N_{t}}\right)^{\gamma}=Q_{t, t+1} E_{t} \lambda_{t}
$$

where I define:

$$
\lambda_{t} \equiv \frac{\Lambda_{t}}{\frac{F_{t}}{N_{t}}}
$$

Inserting into (9) and dividing throughout by $\frac{F_{t+1}}{N_{t+1}}$ :

$$
\begin{aligned}
\frac{\lambda_{t}}{G_{t+1}^{X}}= & E_{t} \beta_{t+1}\left[(1-\eta)\left((1-\alpha)\left[\begin{array}{c}
\frac{1}{1-\alpha \xi} \\
+\Theta\left(\frac{\phi V_{t+1}+(1-\phi) Q_{t+1} V_{t+1}}{N_{t+1}}\right)^{\gamma+1} \frac{\alpha+\gamma}{(1+\gamma)(1-\alpha)(1-\xi(1+\alpha+\gamma))}
\end{array}\right]\right)\right] \\
& +E_{t}\left(1-\delta_{t+1, t+2}\right) \beta_{t+1} \lambda_{t+1}
\end{aligned}
$$

where the (gross) rate of productivity growth is given by:

$$
G_{t+1}^{X} \equiv \frac{\frac{F_{t+1}}{N_{t+1}}}{\frac{F_{t}}{N_{t}}}
$$

Dividing (6) by $L_{t}$ throughout I get:

$$
n_{t+1} G_{t+1}^{L}=\left(1-\delta_{t, t+1}\right) n_{t}+Q_{t, t+1} v_{t}
$$

where I define $1+$ the growth rate of the labor force as:

$$
G_{t+1}^{L} \equiv \frac{L_{t+1}}{L_{t}}
$$




\subsection{The Stochastic Set-Up}

The model has four exogenous variables. These are productivity growth $\left(G^{X}-1\right.$, see equation 21$)$, labor force growth $\left(G^{L}-1\right.$, see equation 23$)$, the discount factor $(\beta)$ and the separation rate $(\delta)$. Empirical testing reveals that $G^{L}$ can be modelled as white noise around a constant value. When I tried to add it as a stochastic variable to the framework below the results were not affected. I thus treat it as a constant. It is the other three variables that inject shocks into this system. These variables are basically the variables that make up the firm's future marginal profits, with higher $G^{X}$ increasing these profits and higher $\beta$ or $\delta$ decreasing them. As mentioned, I do not formulate the underlying shocks structurally. Instead, I postulate that they follow a first-order VAR (in terms of $\log$ deviations from their non-stochastic steady state values):

$$
\left[\begin{array}{c}
\widehat{G}_{t+1}^{X} \\
\widehat{\beta}_{t+1} \\
\widehat{\delta}_{t+1}
\end{array}\right]=\Pi\left[\begin{array}{c}
\widehat{G}_{t}^{X} \\
\widehat{\beta}_{t} \\
\widehat{\delta}_{t}
\end{array}\right]+\Sigma
$$

In the empirical section below I use reduced-form VAR estimates of the data to quantify the coefficient matrix $\Pi$ and the variance-covariance matrix of the disturbances $\Sigma$. Thus the current model is consistent with both RBC-style models that emphasize technology shocks as well as with models that emphasize other shocks.

\subsection{The Non-Stochastic Steady State}

In the non-stochastic steady state the rate of vacancy creation is given by:

$$
\Theta(\phi+(1-\phi) Q)\left(\frac{\phi V+(1-\phi) Q V}{N}\right)^{\gamma}=Q \frac{G^{X} \beta}{\left[1-(1-\delta) G^{X} \beta\right]} \pi
$$

The LHS are marginal costs; the RHS is the match asset value. It is probability of filling a vacancy $(Q)$ times the marginal profits accrued in the steady state. The latter are the product of per-period marginal profits $\pi$ and a discount factor $\frac{G^{X} \beta}{1-G^{X} \beta(1-\delta)}$ that takes into account the real rate of interest, the rate of separation and productivity growth.

Labor market flows are given by: 


$$
\left(\delta+G^{L}-1\right)=\frac{m}{n}=\frac{Q v}{n}
$$

This expression equates the rate of increase in employment through matching with the sum of the rates of separation and increase in the labor force. From this equation the rate of unemployment in equilibrium is given by:

$$
u=\frac{\delta+\left(G^{L}-1\right)}{\delta+\left(G^{L}-1\right)+P}
$$

\subsection{Log-Linear Approximation}

I log-linearly approximate the deterministic version of the F.O.C in the neighborhood of the steady state. For each variable $Y$, I use the notation $\widehat{Y}_{t}=\frac{Y_{t}-Y}{Y} \approx \ln Y_{t}-\ln Y$ where $Y$ is the steady state value, so all variables are $\log$ deviations from steady state.

Approximating the intratemporal condition (18), the intertemporal condition (20), and the dynamic equation for employment (22) and combining all of them I get (the technical appendix available at http://www.tau.ac.il/ yashiv/performance.html spells out the complete derivation):

$$
\left[\begin{array}{c}
\widehat{n}_{t+1} \\
\widehat{\lambda}_{t+1}
\end{array}\right]=W\left[\begin{array}{c}
\widehat{n}_{t} \\
\widehat{\lambda}_{t}
\end{array}\right]+R\left[\begin{array}{c}
\widehat{G}_{t+1}^{X} \\
\widehat{\beta}_{t+1} \\
\widehat{\delta}_{t+1, t+2}
\end{array}\right]+Q\left[\begin{array}{c}
\widehat{G}_{t}^{X} \\
\widehat{\beta}_{t} \\
\widehat{\delta}_{t, t+1}
\end{array}\right]
$$

where $W, R, Q$ are matrices which are functions of the parameters and steady state values.

This system is a first-order, linear, difference equation system in the state variable $\widehat{n}$ and the

co-state $\widehat{\lambda}$ with three exogenous variables, $\widehat{G}^{X}, \widehat{\beta}$ and $\widehat{\delta}$. The matrices of coefficients are defined by the parameters $\alpha, \Theta, \gamma, \phi, \mu, \sigma$ and $\eta$ and by the steady state values of various variables. The solution of this system enables us to solve for the control variable - vacancies, and for other variables of interest, such as unemployment, hires, the matching rate, and the labor share of income.

\section{U.S. Labor Market Data}

In coming to relate the model to U.S. data, a number of important issues arise. The following discussion shows that the different variables have multiple representations in the data and some 
are not consistent with the concepts of the model. The idea is to select those series that do match these concepts and to examine alternative representations wherever relevant.

I proceed as follows: in 4.1 I discuss the relevant pool of searching workers, who are defined as $u$, unemployed, in the model; in $4.2 \mathrm{I}$ conduct a similar discussion for job vacancies $v$; in 4.3 I consider the flow of hires $m$ and in 4.4 the relevant wage data $s$; in $4.5 \mathrm{I}$ briefly discuss other data series; finally, in 4.6 I present summary statistics, including second moments, and discuss the properties of the data in terms of persistence, volatility, and co-movement. I end the section with a discussion of the findings of recent literature that questions the model's ability to fit these data.

\subsection{The Relevant Pool of Unemployment}

In order to see how the model relates to the data, a key issue that needs to be resolved is the size of the relevant pool of searching workers. The question is whether this pool is just the official unemployment pool or a bigger one. The model speaks of two states - employment and unemployment; in the model matches are flows from unemployment to employment and separations are flows from employment to unemployment. ${ }^{5}$ In the actual data - taken from the CPS - several important issues arise:

(i) Flows between the pool out of the labor force and the labor force, including flows directly to and from employment, are sizeable. Blanchard and Diamond (1990) report that in worker flows data - adjusted according to the methodology of Abowd and Zellner (1985) and covering the period 1968-1986 - unemployment to employment flows are only slightly bigger - at 1.6 million workers per month - than out of the labor force to employment flows, at 1.4 million per month. More recent data, computed using the methodology of Bleakley et al (1999) for the period 1976-2003, indicate that unemployment to employment flows are on average 1.9 million workers per month, while out of the labor force to employment flows are 1.5 million workers per month on average.

(ii) Clark and Summers (1979) have argued that there is substantial misclassification of unemployment status and that "many of those not in the labor force are in situation effectively equivalent to the unemployed" (p.29), providing several measures to substantiate this claim. One implication that emerges from their study is that including such misclassified workers in the unem-

\footnotetext{
${ }^{5}$ Additionally, labor force growth (with new participants joining the unemployment pool) is an exogenous variable.
} 
ployment pool generates a longer average duration for unemployment and hence a smaller matching hazard ( $P$ in the model) relative to the official unemployment pool. Data collectors were aware of this issue: following the recommendations of the Gordon committee, which recognized that there could be some form of "hidden unemployment," beginning in January 1967 the CPS included questions on out of the labor force people who could potentially be defined as unemployed. This generated a quarterly series on people that responded affirmatively to the question if they "wanted a job now" (I report this series below). Castillo (1998) [who offers a detailed discussion and additional references concerning the CPS procedure] reports, using 1994 data, that about 30\% of this pool actually searched for work in the 12 months prior to the survey, and $47 \%$ were in the prime age category (25-54).

(iii) Working on the re-designed CPS data in the period 1994-1998, Jones and Riddel (2000) further demonstrate the importance of these distinctions. Key results include estimates of the hazard rates for three worker groups: the unemployed, the marginally attached, and the unattached, the last two being officially classified as out of the labor force. Their monthly hazard rates are 0.20 0.35 for the unemployed, 0.10-0.20 for the marginally attached, and below 0.05 for the unattached. Various tests indicate that these are indeed three distinct states.

(iv) The out of the labor force flows exhibit markedly different cyclical properties relative to flows between employment and unemployment: the unemployment to employment flows are countercyclical or a-cyclical while the out of the labor force to employment flows are pro-cyclical. ${ }^{6}$

Given this evidence, it appears natural to consider pools of workers outside the labor force when coming to study labor market dynamics and worker flows. The question is how to add the unobserved 'unemployment' pool from out of the labor force to the 'official' pool of unemployment.

\footnotetext{
${ }^{6}$ There are two major data sets on worker flows: Blanchard and Diamond (1990, see in particular Figures 1,10 and 11) and Bleakley et al (1999).

The unemployment to employment flows are negatively correlated with the rate of employment ( -0.91 for the 1968-1986 Blanchard and Diamond data and -0.50 for the 1976-2003 Bleakley et al data) and negatively correlated or uncorrelated with GDP per capita (-0.61 for the 1968-1986 data and 0.12 for the 1976-2003 data).

The out of the labor force to employment flows are positively correlated with the rate of employment (0.56 for the 1968-1986 Blanchard and Diamond data and 0.70 for the 1976-2003 Bleakley et al data) and with GDP per capita (0.56 for the 1968-1986 data and 0.76 for the 1976-2003 data).
} 
Blanchard and Diamond $(1989,1990)$ suggest that the relevant additional pool is made up of the people described in point (ii) above. Another method to estimate this pool is to compute the number of people within the out of the labor force group that would generate matching rates $\left(\frac{M}{U}\right)$ identical to those that are observed for unemployment to employment flows. ${ }^{7}$ Figure 1 shows the resulting two new series, as well as the official unemployment rate, for the period in which the series exist.

\footnotetext{
${ }^{7}$ This estimate - based on the relationship $P=\frac{M}{U}-$ is computed as follows: first note that

$$
P^{U E}=\frac{M^{U E}}{U}
$$
}

where $M^{U E}$ is the unemployment to employment flow and $U$ is the official pool. Then, assuming $P^{U E}$ holds true, and using data on out of the labor force to employment $M^{N E}$ flow, we compute:

$$
U^{*}=\frac{M^{U E}+M^{N E}}{P^{U E}}=U\left(\frac{M^{U E}+M^{N E}}{M^{U E}}\right)=U\left(1+\frac{M^{N E}}{M^{U E}}\right)
$$

The official rate is given by $\frac{U}{N+U}$ while the new rate is given by $\frac{U^{*}}{N+U^{*}}$. The relation between the two series in rates is thus:

$$
\frac{\frac{U^{*}}{N+U^{*}}}{\frac{U}{N+U}}=\frac{U^{*}}{U} \frac{N+U}{N+U^{*}}=\left(1+\frac{M^{N E}}{M^{U E}}\right) \frac{1+\frac{U}{N}}{1+\frac{U^{*}}{N}}
$$




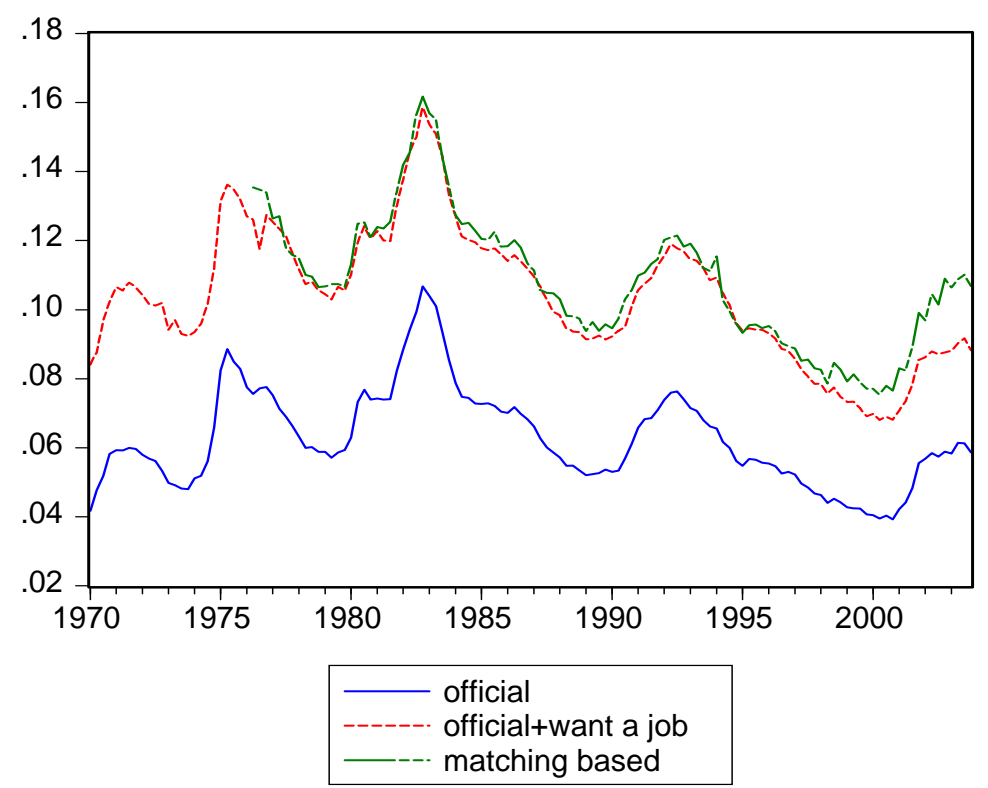

Figure 1: Alternative unemployment series (rates)

The official rate in this period has a mean of $6.3 \%$. The series that adds workers who said they want a job has a mean of $10.4 \%$ and the second series has a mean of $10.9 \%$ of the relevant labor force. As can be seen in the figure, the series are highly correlated: the new series have a 0.97 correlation between them and high correlations with the official rate $(0.98)$.

These series, however, are likely to be lower bounds on the relevant unemployment pool: the first series was constructed in reference to indicating a desire for a job now; this precludes other out of the labor force groups who wish to work at a future date, for example people in training or in school. In terms of our two-state model these people could be subsequently flowing directly to the employment pool and thus have to be classified as unemployed. As to the second series, the data support the proposition that the matching rate $\left(P=\frac{M}{U}\right)$ used to generate it is an upper bound on the relevant rate, as persons out of the labor force are likely to experience higher unemployment durations. Hence the resulting unemployment pool is a lower bound on the relevant pool. For example, analysis of 1994 data in Castillo (1998) shows that while matching rates for the officially unemployed were 0.53 , they were only 0.31 for the "wanted a job" pool. The issue, then, is how 
many non-employed workers does one add from out of the labor force to the already expanded pools shown in Figure 1.

The strategy I use in the empirical work is as follows. I look at the three "natural" candidate series: (i) official unemployment, (ii) official unemployment and the "want a job" category (depicted above) and (iii) the entire working age population. As the relevant pool may lie between the second and third cases and as no measured pool is available, I look at two additional specifications that try to approximate that pool. Thus, starting from case (ii) I gradually add parts of the remaining workers from the out of the labor force pool. Table 1 provides sample statistics of these five series.

\section{Table 1}

Two features stand out: while the mean of the series evidently rises with the expansion of the pool, the volatility hardly changes going from the official + want a job pool to the larger pools; the series are highly correlated (though the correlation slightly declines as the pool expands).

In what follows, I look at the properties of the data under these different specifications. In Section 5 below, I compare the performance of the calibrated model against these alternative specifications and decide on a benchmark specification for the subsequent analysis. ${ }^{8}$

\subsection{Job Vacancies}

The relevant concept of vacancies in the model is the one relating to those vacancies that are to be filled with workers from outside the employment pool (I shall denote it by $V^{U N}$ ). But the available and widely-used data series pertains to another concept, which also includes vacancies that are subsequently filled with workers moving from job to job (to be denoted by $V_{t}^{N N}$ ). ${ }^{9}$ Simply this can be expressed as follows:

\footnotetext{
${ }^{8}$ Previous papers have taken on a variety of approaches to this issue, which are special cases of the current examination: Blanchard and Diamond (1989) have essentially considered the relevant pool to be the first series reported in Figure 1, Merz (1995) took the official pool of unemployment, and Andolfatto (1996) considered the entire working age population as unemployed in the model.

${ }^{9}$ This should not be taken to mean that firms post two types of vacancies. The idea is just to say that some vacancies are ex-post filled by previously unemployed workers and the rest by previously employed workers moving directly from job to job.
} 


$$
V_{t}^{t o t}=V_{t}^{U N}+V_{t}^{N N}
$$

The $V_{t}^{\text {tot }}$ series in the U.S. economy has two representations: one is the index of Help Wanted advertising in newspapers published by the Conference Board; this series was analyzed and discussed in Abraham (1987). A newer series is the job openings series available from the BLS since December 2000 using the Job Openings and Labor Turnover Survey (JOLTS). ${ }^{10}$ The two series have a correlation of 0.88 over 37 monthly observations. The following figure plots these two vacancies series as well as a third series: the gross flows of workers from outside employment (unemployment and out of the labor force) to employment, which can be taken to represent $Q \times V^{U N}$. The latter was recently compiled at the Boston Fed based on CPS data [see the Data appendix below and Bleakley et al (1999)]. The figure shows all three series normalized:

\footnotetext{
${ }^{10} \mathrm{~A}$ job is "open" only if it meets all three of the following conditions: (i) a specific position exists and there is work available for that position; the position can be full-time or part-time, and it can be permanent, short-term, or seasonal; (ii) the job could start within 30 days, whether or not the establishment finds a suitable candidate during that time; and (iii) there is active recruiting for workers from outside the establishment location that has the opening.
} 


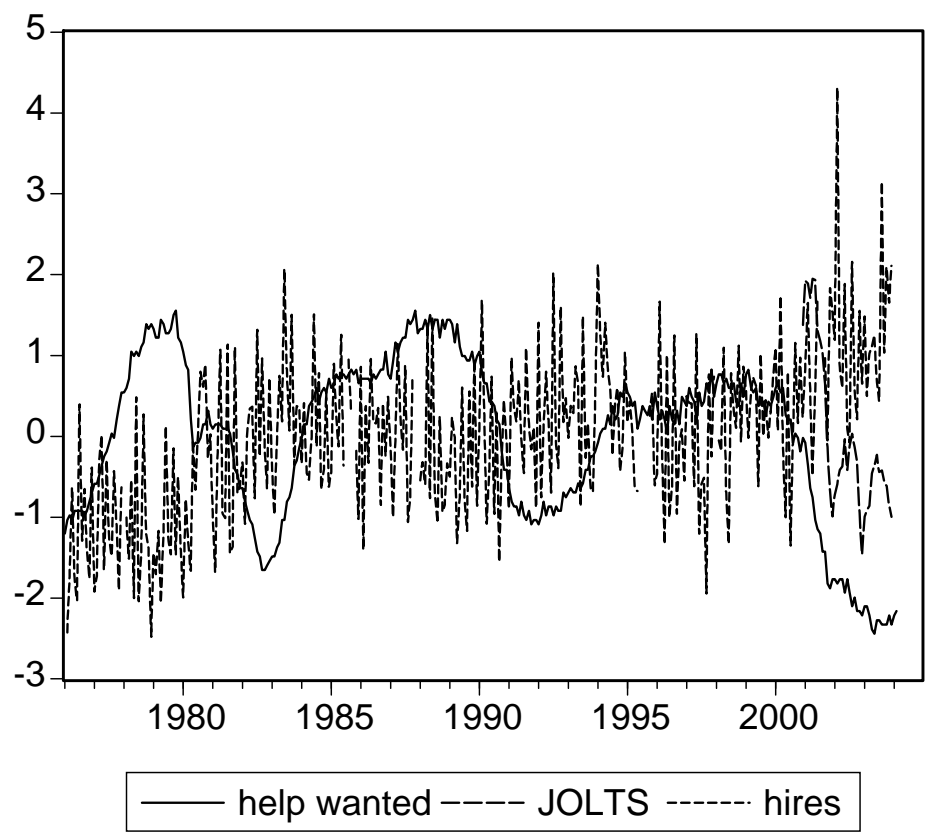

Figure 2: Hiring vs. the two vacancy measures (normalized)

The hiring flows series is negatively correlated with the two vacancy series: -0.27 with the JOLTS series and -0.36 with the Help Wanted ads series. The flows series also appears to be much less persistent than the vacancies series.

Table 2 presents the coefficient of variation (or standard deviation) and autocorrelation for the two vacancy series and for the hiring series. It does so first for their respective individual samples and then for the common sample period. It reports the variables in levels, in logged HPfiltered form, and subsequently in terms of their ratios to unemployment, which can be taken as a measure of market tightness.

\section{Table 2}

Compared to the volatility of the Help Wanted Index, hiring volatility is about a seventh in levels, a fifth in HP filtered terms, and about a third in ratios to unemployment terms. It is 
similarly less volatile than the JOLTS data series. In terms of persistence, hiring is substantially less persistent in levels and even more so in HP-filtered terms; it has similar persistence in market tightness terms.

This comparison - between $V^{t o t}$ and $Q \times V^{U N}$ - suggests that $V^{t o t}$ may either be very different from $V^{U N}$ or that the behavior of $Q$ generates these discrepancies. Without direct measures of $V^{U N}$ it is not possible to determine which explanation holds true but there is indirect evidence. Using the data on $Q \times V^{U N}$ shown above one can run a regression of the matching function as follows:

$$
\ln \left(\frac{Q_{t, t+1} V_{t}^{U N}}{N_{t}}\right)=\ln \widehat{\mu}+\widehat{\sigma} \ln \left(\frac{U_{t}}{N_{t}}\right)+(1-\widehat{\sigma}) \ln \left(\frac{V_{t}}{N_{t}}\right)
$$

Previous estimates of the matching function - as surveyed by Petrongolo and Pissarides (2001) and as exemplified by the Blanchard and Diamond (1989) analysis - indicate that $\widehat{\sigma}$ is around 0.4 to 0.5 . This means that the regression should yield around 0.4 to 0.5 for the coefficient of $\ln \left(\frac{U_{t}}{N_{t}}\right)$ and around 0.6 to 0.5 for the coefficient of $\ln \left(\frac{V_{t}}{N_{t}}\right)$. Using the Help Wanted index for $V$ one gets an estimate of around 0.3 for the coefficient of $\ln \left(\frac{U_{t}}{N_{t}}\right)$ but only 0.1 for the coefficient of $\ln \left(\frac{V_{t}}{N_{t}}\right)$, irrespective of the estimation technique (OLS, TSLS or GMM) or the instruments used. The extremely low value for the latter coefficient implies that hiring rates (from outside employment, i.e. $\frac{Q_{t, t+1} V_{t}^{U N}}{N_{t}}$ ) do not relate well to the vacancy rate when the latter is measured by the Help Wanted Index. This is consistent with the interpretation that the behavior of the Help Wanted Index, which relates to the broader $V^{\text {tot }}$, is different from the behavior of the relevant series here, $V^{U N}$.

Another exercise is to compute a "reconciling $Q$ " to be denoted $Q_{t, t+1}^{s i m}$ i.e.

$$
Q_{t, t+1}^{s i m}=\frac{M_{t, t+1}^{U N}}{V_{t}^{t o t}}
$$

which makes the series $\left(V^{t o t}, V^{U N}\right)$ compatible and then see whether it reasonably fits with the model. The model predicts the following relationship:

$$
Q_{t, t+1}=\mu\left(\frac{V_{t}}{U_{t}}\right)^{-\sigma}
$$

Note that the "reconciling," simulated $Q$ can be written as: 


$$
Q_{t, t+1}^{s i m}=\frac{M_{t, t+1}^{U N}}{V_{t}^{t o t}}=Q_{t, t+1}^{U N} \frac{V_{t}^{U N}}{V_{t}^{t o t}}
$$

Note that as $\frac{V_{t}^{U N}}{V_{t}^{\text {tot }}} \rightarrow 1$, then $Q_{t, t+1}^{s i m} \rightarrow Q_{t, t+1}^{U N}$. Running a regression based on the model's formulation i.e.:

$$
\ln Q=\ln k-a \ln \left(\frac{V_{t}}{U_{t}}\right)
$$

using $Q^{\text {sim }}$ for $Q$ and the Help Wanted Index for $V$, I get an estimate of $a$ of about 0.7, higher than the 0.4 to 0.5 range cited above for $\sigma$. In other words the simulated $Q$ is more responsive to variations in market tightness than usual estimates of $\sigma$ indicate. This is likely to occur the more different are $V_{t}^{U N}$ and $V_{t}^{\text {tot }}{ }^{11}$

Another body of evidence is to be found in recent work on gross worker flows. Fallick and Fleischman (2004), using CPS data in the period 1994-2003, find that employment to employment flows are large; in fact $2 / 5$ of new jobs represent employer changes. They also show that the cyclical properties of employment to employment flows are very different from those of the flows into and out of employment. Nagypal (2004), using micro data sets, provides additional, supporting evidence on the prevalence of job to job worker flows. Hence $V^{N N}=V^{t o t}-V^{U N}$ appears to be of substantial magnitude. Pissarides (1994) offers one possible explanation for the higher volatility of

\footnotetext{
${ }^{11}$ The regression postulates

$$
Q_{t, t+1}^{s i m}=k\left(\frac{V_{t}^{t o t}}{U}\right)^{-a}
$$
}

The model posits:

$$
Q_{t, t+1}^{s i m}=\mu\left(\frac{V^{U N}}{U}\right)^{-\sigma} \frac{V_{t}^{U N}}{V_{t}^{t o t}}
$$

Hence:

$$
k\left(\frac{V_{t}^{t o t}}{U}\right)^{-a}=\mu\left(\frac{V^{U N}}{U}\right)^{-\sigma} \frac{V_{t}^{U N}}{V_{t}^{t o t}}
$$

Taking logs and re-arranging we get:

$$
a=\sigma-\frac{\ln \mu-\ln k}{\ln \left(\frac{V_{t}^{t o t}}{U}\right)}-\frac{(1-\sigma) \ln \left(\frac{V_{t}^{U N}}{V_{t}^{t o t}}\right)}{\ln \left(\frac{V_{t}^{t o t}}{U}\right)}
$$

Only when $\frac{V_{t}^{U N}}{V_{t}^{\text {tot }}}=1$ and when $\mu=k$ will the estimate $a$ equal $\sigma$. 
vacancies that relate to both job to job movements ( $V^{N N}$ in the above notation) and to movements from out of employment $\left(V^{U N}\right)$ : these "broader" vacancies (i.e. $V^{t o t}$ ) are more responsive to productivity changes and hence are more volatile. The reason for the increased responsiveness is that employed workers, as well as unemployed workers, change their search activities following productivity changes, thereby affecting the incentives of firms in opening job vacancies.

The conclusion from this discussion is the following: the present model, being an aggregate, representative firm-type of model, does not deal with job to job movements (as is also the case for the recent literature cited below), and thus the Help Wanted Index is not the relevant series to use as it probably does not behave like the relevant series $\left(V^{U N}\right)$. Given that the latter is unobserved, I resort to focusing on the observed worker flow series (i.e. on $Q \times V^{U N}$ ) whenever comparing the model to the data (though the model will generate predictions also with respect to $V$ ). The above discussion also implies that care must be taken when using or discussing vacancy data in the U.S. economy.

\subsection{The Flow of Hires and the Worker Hazard Rate}

The discussion on the relevant pool of unemployment makes it clear that it is important to analyze the flow of matches or hires using out of the labor force to employment flows as well as unemployment to employment. This implies that in addition to different unemployment pools $U$, there will be different matching flows $M$ and consequently different worker hazard rates $P=\frac{M}{U}$. Figure 3 presents these different rates. 


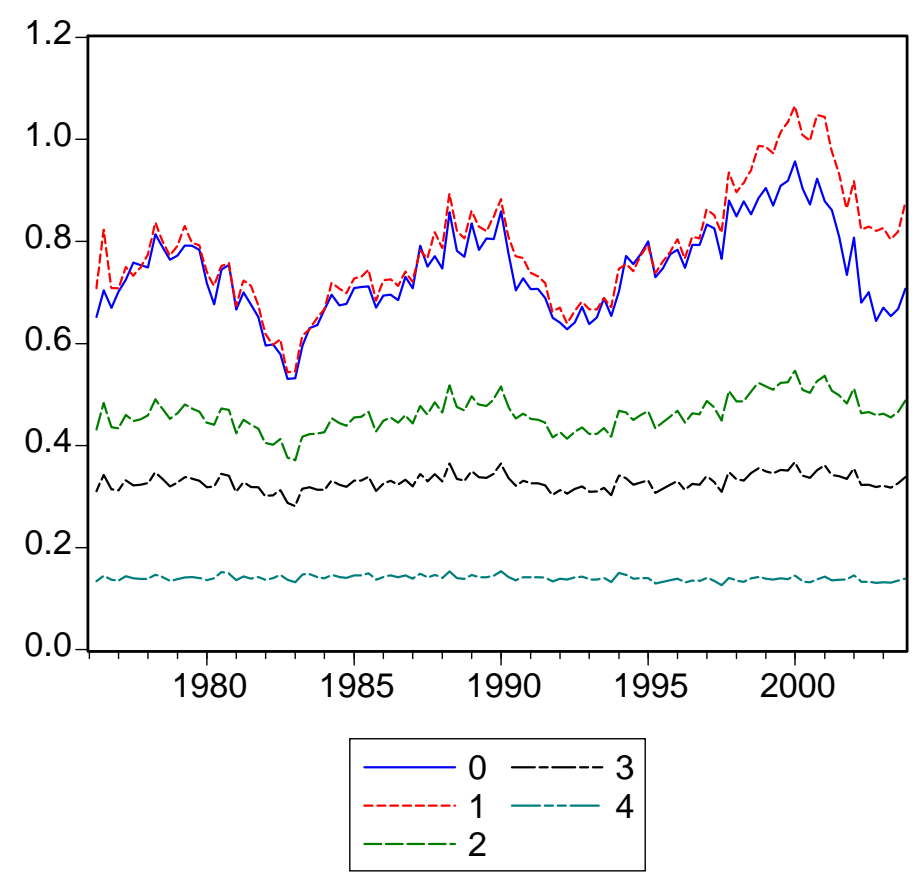

Figure 3: Alternative specifications of the hazard rate $P$

The 0 and 1 series represent the ones derived from the official rate and from the official+want a job series respectively, both depicted in Figure 1 above. They imply unemployment durations of 17.4 weeks and 16.5 weeks respectively. In comparison, official BLS data on duration indicate 15.1 weeks on average (with 2.5 weeks standard deviation) in the same period. The other series specifications 2,3 and 4 - evidently imply higher durations: 28.0,39.0 and 91.8 weeks respectively. All rates are highly correlated with the notable exception of specification 4, which is almost uncorrelated with the 0 and 1 specifications (correlations of 0.10 and -0.03 respectively) and weakly to moderately correlated with the 2 and 3 specifications ( 0.23 and 0.53 respectively).

The following table compares these estimates, based on aggregate worker flow and nonemployment stock data, to the estimates of the afore-cited Jones and Riddell (2000) micro-based, CPS 1994-1998 study: 


\section{Table 3}

The official pool has a slightly higher hazard than the upper bound of the Jones and Riddel estimate (i.e. 0.80 compared to 0.73 ). From the three intermediate pools, specification 2 has a hazard rate (0.47) that is consistent with a mixture of the unemployed and the marginally attached. The largest pool, that includes all non-employed workers (specification 4 here), has a hazard rate (0.14) that seems to be consistent with a mixture of the unattached with the other two groups.

\subsection{Wages}

The existence of diverse data series for wages with different cyclical properties was noted by several papers [see in particular Abraham and Haltiwanger (1995), Abraham, Spletzer and Stewart (1999), and Krueger (1999)]. The discussion in these papers does not lead to any definite conclusion as to which series is the most appropriate. Figure 4 illustrates one aspect of this issue by plotting BEA series of the labor share $s=\frac{W}{F / N}$, once using total compensation ${ }^{12}$ and once using wages.

\footnotetext{
${ }^{12}$ Defined as total compensation of employees relative to GDP; this includes, beyond wages and salaries, supplements such as employer contribution for employee pension and insurance funds and employer contribution for goverment social insurance.
} 


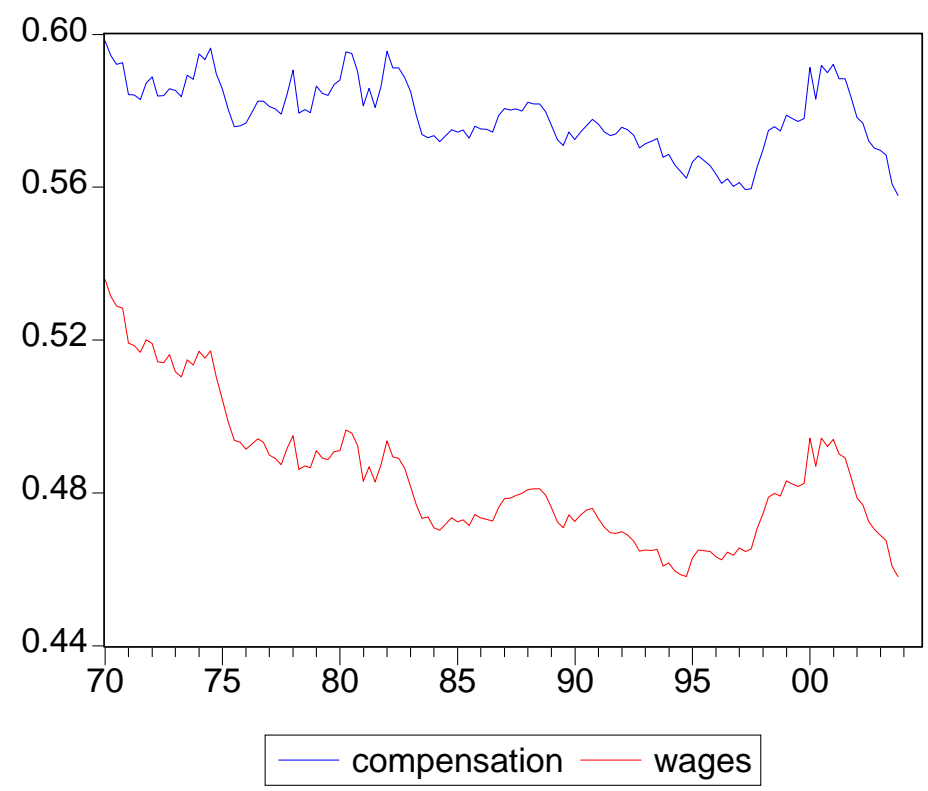

Figure 4: the labor share $s$

The series are correlated 0.83 but have a number of important differences: the wage series declines more over time, is lower by ten percentage points on average, and displays much more variation (coefficient of variation of 0.037 relative to 0.016 for the other series). It should also be noted that both series have very weak correlation with the cycle: the compensation series has -0.05 correlation with the employment rate and the wage series has a 0.12 correlation.

In what follows I use the compensation series as it takes all firm's wage-related costs, which is the relevant concept in the model.

\subsection{Other Data Series}

Figure 5 shows the other data series to be used in the empirical work below: productivity growth $G^{X}$ (gross rate), the discount factor $\beta$, and the separation rate $\delta$ (separately for the official unemployment specification $\delta_{0}$ and for the others $\delta$ ). 


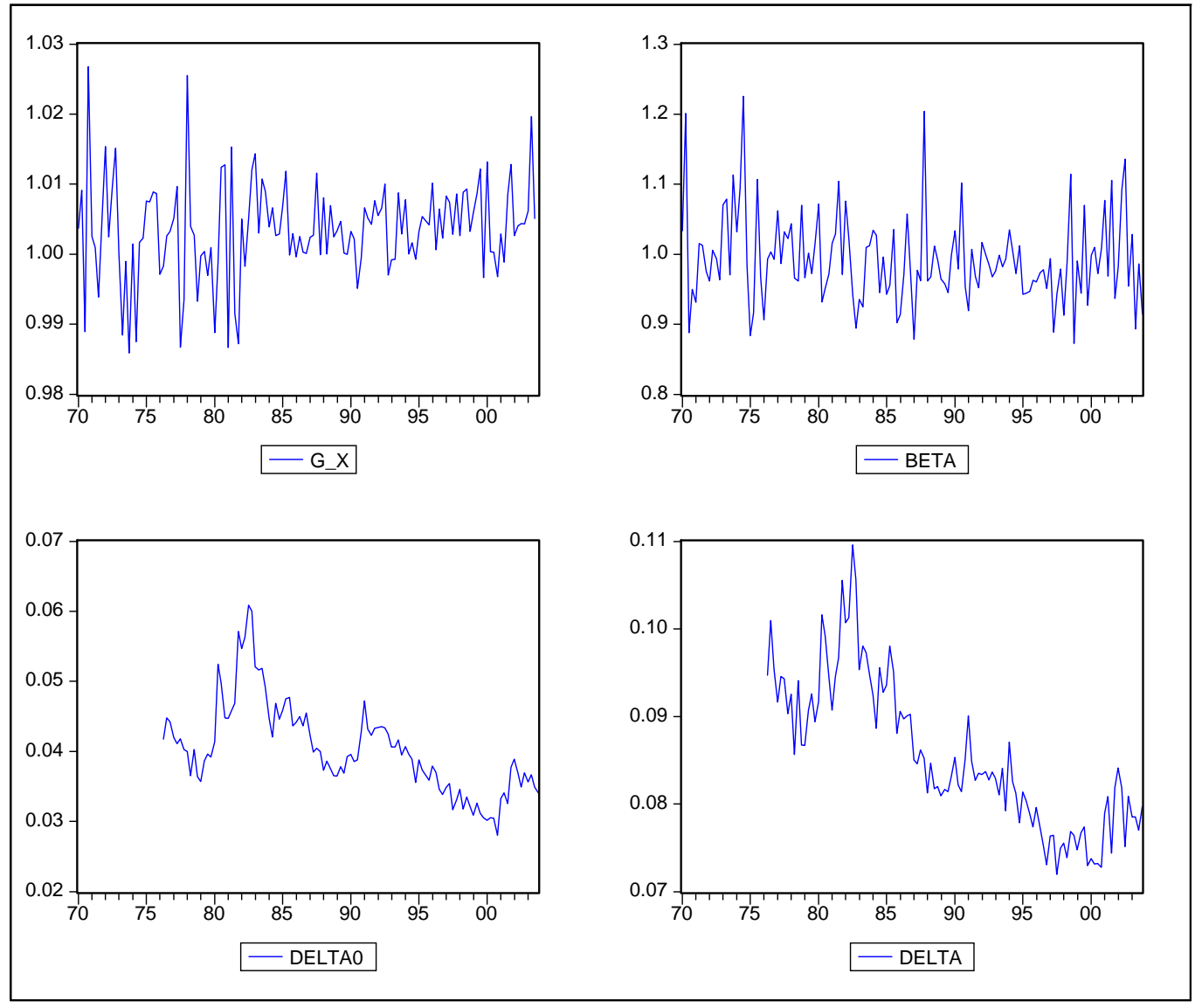

Figure 5: $G^{X}, \beta, \delta_{0}, \delta$

For productivity growth I take the rate of change of GDP per worker; for the discount factor I take $\beta=\frac{1}{1+r}$ where $r$ is the cost of firm finance (weighted average of equity finance and debt finance); for the separation rate I take the flow from employment divided by the stock of employment.

\subsection{Data Properties}

Table 4 reports the first two moments of all relevant data series, including measures of persistence and co-movement. When looking at these moments it is important recall that the business cycle is most clearly manifested in the labor market - there is high correlation between employment and output and their volatility is similar. The table describes the key moments across the different 
specifications of the unemployment pool (and the labor force). Column 0 is the benchmark specification - it uses the official unemployment pool. Column 1 is the 'lower bound' specification with unemployment including the official pool and those workers out of the labor force indicating that they "want a job." Columns 2 and 3 add to column 1 a fraction - 15\% and 30\% respectively - of the remaining persons out of the labor force. Column 4 considers the entire working age population as the labor force.

\section{Table 4}

The following major properties can be said to characterize the data:

Persistence. All the main labor market variables are persistent: the rate of unemployment (and thus employment), hiring, separation, and the wage share all exhibit high persistence. There is some variation across the different cases: unemployment persistence increases slightly as the unemployment pool is expanded and the reverse is true for hiring and separation. At the same time productivity growth and the discount factor are not persistent at all. Note that one of the three driving shocks - the separation rate - is persistent.

Volatility.

(i) The table indicates differential volatility across variables and across specifications of the pool of searching workers. With only the officially unemployed considered searching (column 0), the volatility of the unemployment rate is the highest at 0.22 in terms of log levels; less volatile are the hiring and separation rates, which have comparable volatility at about 0.13-0.16; the discount factor has a volatility of 0.06 in the same terms; the volatility of the rate of employment $\left(n=\frac{N}{L}\right)$ is of the same order of magnitude as that of the wage share at around 0.015 (in the same log terms); productivity growth at 0.007 has even lower volatility. Note that this is somewhat akin to investment behavior: the capital stock (here the employment stock) is much less volatile than investment (here the hiring flow). Note too the relatively high volatility of the rate of separation and of the discount factor, which are driving factors. 
(ii) When moving across columns to a broader specification of the pool of searching workers some patterns change: in relative terms, hiring and separation become more volatile (at 0.07-0.10 in column 4) than unemployment (at 0.07 ). In absolute terms the employment rate becomes more volatile while unemployment, hiring and separation (in rates) all become less volatile.

Co-movement.

(i) Hiring rates $(m)$ co-vary positively with the unemployment rate, while the worker hazard rate usually co-varies negatively with the same variable. This means that hiring flows (in rates) are counter-cyclical (see the discussion of the various unemployment pools above) ${ }^{13}$ but job-finding rates $P=\frac{m}{u}$ are pro-cyclical. Note that in recessions $U$ rises and $P$ falls; hence $\frac{M}{L}=\frac{P \cdot U}{N+U}$ rises as the effect of a rising $U$ overcomes the fall in $P$ and any change in $L$.

(ii) Separation rates $(\delta)$ are counter-cyclical. Note that hiring and separation rates move together, unlike the widely-known negative correlation between job creation and job destruction in the manufacturing sector. This issue is discussed in Nagypal (2004).

(iii) The labor share in income $(s)$ varies between a-cyclicality and counter-cyclicality (with respect to employment) according to the specification of the labor force. Throughout it covaries positively with the hiring rate. This means that when $\frac{F}{N}$ rises in booms, the wage $(W)$ rises by less and thereby the labor share $(s)$ declines.

(iv) There is low correlation between employment and productivity growth, a fact which has received considerable attention in the RBC literature Note that the data here are in terms of the $\log$ of the employment rate and the first differences of the log of productivity but that they display essentially the same co-movement pattern that is discussed in the business cycle literature in terms of HP-filtered and logged productivity and employment.

(v) Employment has low co-variation with the discount factor.

Note some non-intuitive aspects of these data moments: in booms hiring and separation rates fall and the labor share either does not change or falls. Hiring is strong at the same time as the share of wages is high.

Recently, some authors have questioned the ability of the model to explain these data. Cole and Rogerson (1999) found that the model can account for business cycle facts only if the average

\footnotetext{
${ }^{13}$ This is also true for logged and HP-filtered variables.
} 
duration of unemployment is relatively high (9 months or longer) and substantially longer than average duration in BLS data on the unemployed. The intuition for this critique is the following: the data point to a negative correlation between job destruction and job creation. Job destruction leads to higher unemployment thereby raising the incentives for job creation. In order for job creation to be contemporaneously negatively correlated with job destruction there has to be a mitigating factor and that role is played by the relatively low worker hazard rate, which is the inverse of unemployment duration.

Shimer (2004) showed that in the standard matching model productivity shocks of empirically plausible magnitude cannot generate the observed, large cyclical fluctuations in unemployment and vacancies. The key reason for this result is that the standard model assumes that wages are determined by Nash bargaining, which in turn implies that wages are "too flexible." Thus, for example, following a positive productivity shock wages increase, absorbing the shock, thereby dampening the incentives of firms to create new jobs. In particular, while the model predicts roughly the same volatility of the vacancy to unemployment ratio and of productivity, the data indicate this ratio is actually 18 times more volatile.

Veracierto (2002) has shown that the model fails to simultaneously account for the observed behavior of employment, unemployment and out of the labor force worker pools. Analyzing the $\mathrm{RBC}$ model with search and matching that makes an explicit distinction between these states, he finds that the model has serious difficulties in reproducing the labor market dynamics observed in U.S. data. In particular, employment fluctuates as much as the labor force while in the data it is three times more variable, unemployment fluctuates as much as output while in the data it is six times more variable, and unemployment is acyclical while in the data it is strongly countercyclical. An underlying reason is that search decisions respond too little to aggregate productivity shocks.

Fujita (2004) conducted empirical tests showing that vacancies are much more persistent in the data than the low persistence implied by the model.

Taken together these studies cast doubt on the model's ability to fit the data on two key dimensions: the volatility and duration of unemployment, and the volatility and persistence of vacancies. They also point to serious shortcomings in accounting for aggregate wage behavior.

I turn now to the calibration of the model under the different data specifications and the 
evaluation of its performance against the data.

\section{Calibration and Model-Data Fit}

In this section I calibrate the model and examine its performance, taking into account the alternative formulations of the pool of searching workers discussed above. I begin by discussing calibration values in sub-section 5.1. I then (5.2) examine the performance of the model.

\subsection{Calibration}

Calibration of the model requires the assignment of values to the parameters of the production, hiring costs, and matching functions as well as to the wage bargain, to the steady state values of the exogenous variables (labor force growth, productivity growth, the discount factor and the separation rate) and to the steady state values of the endogenous variables. To do so I use, wherever possible, results from econometric studies and average values of the longest sample period available. I then solve for all other values using the steady state relations (equations 25 and 26).

There are three structural parameters that are at the focal point of the model and that reflect the operation of frictions. These are the matching function parameter $\sigma$ (elasticity of unemployment), the wage parameter $\eta$, and the hiring function convexity parameter $\gamma$.

For $\sigma$ I use Blanchard and Diamond's (1989) estimate of 0.4. Structural estimation of the model using U.S. corporate sector data in Merz and Yashiv (2004) indicates a value of $\gamma$, the convexity parameter of the hiring cost function, around 2, i.e. a cubic function $(\gamma+1=3)$ for hiring costs. These costs fall on vacancies and on actual hires, with $\phi$ being the weight on the former. I follow the estimates in Yashiv (2000a) and set it at 0.3.

The wage parameter $\eta$ depends on the asymmetry of the bargaining solution $(\xi)$ and on the replacement ratio $(\tau)$. This is obviously a difficult case for calibration as $\xi$ is not directly observed and $\tau$ depends not only on the value of benefits relative to wages but also on actual take-up rates. Following Anderson and Meyer (1997) I postulate a value of 0.25 for the latter; to test for robustness I tried a far higher value, finding that this change has a very small effect on the resulting moments. For $\xi$ rather than imposing it, I solve it out of the steady state relations. 
For the production function parameter $\alpha$ I use a fairly traditional value of 0.68 , which is also the structural estimate of this parameter in Merz and Yashiv (2004).

For the values of the exogenous variables I use sample average values as follows: in quarterly terms the sample average of the rate of productivity growth $\left(G^{X}-1\right)$ is $0.35 \%$; the sample average rate of labor force growth $\left(G^{L}-1\right)$ varies according to the definition of the unemployment pool between $0.43 \%$ and $0.36 \%$; the stochastic discount factor $\beta$ - defined as the weighted price of capital (equity and debt financed) - has a sample average of 0.993 , which is close to the value used in many business cycle studies; the sample average for the separation rate $\delta$ is $8.5 \%{ }^{14}$.

For the steady state values of the endogenous variables, given the discussion above on the relevant unemployment pool, I modify $n$ and $u$ according to the specifications used above. Calibration of $Q$, the matching rate for vacancies, is problematic as there are no wide or accurate measures of vacancy durations for the U.S. economy. Using a 1982 survey, Burdett and Cunningham (1998) estimated hazard functions for vacancies both parametrically and semi-parametrically finding that the general form of the hazard function within the quarter is non-mononotic; based on their estimates the quarterly hazard rate should be in the range of $0.8-1$. I thus take $Q=0.9$ which is also the value used by Merz (1995) and Andolfatto (1996). This implies a certain steady state value for the vacancy rate $(v)$. I use the average of the labor share in income $s$ which is 0.58 .

With the above values, I solve the steady state relations (25-26) for the steady state vacancy rate $v$, the hiring cost scale parameter $\Theta$, the matching function scale parameter $\mu$, and the wage parameter $\xi$. I can then solve for the steady state values of market tightness $\frac{v}{u}$, the worker hazard rate $P$, per period profits $\pi$ and the match asset value $\lambda$.

The following table summarizes the calibrated values for the different specifications of the unemployment pool.

\section{Table 5}

Note two features of the implied results:

\footnotetext{
${ }^{14}$ For the case of the official unemployment pool I use $\delta=4 \%$ reflecting the rate of separation from employment to this pool only.
} 
(i) The implied wage parameter $\eta$, encompassing the worker bargaining strength and the replacement ratio, varies between 0.4 and 0.6 across specifications.

(ii) Across specifications 1-4, per period profits $(\pi)$ are around 0.07-0.13 (in average output terms) and the asset value of the match $(\lambda)$ is around 0.7-1.5. Given that $s=0.58$ this means that asset values are about $1.2-2.6$ the labor share in income. In other words the match is worth around 1 to 2.5 quarters of wages in present value terms. This quantification of asset values is based on the values of panel (a). The latter include three values which are have not been much investigated in the literature: the vacancy match rate $Q$ and the parameters $\phi$ and $\gamma$ of the hiring cost function. When varying the latter values within reasonable ranges, there was no significant change in the results. Hence the steady state calibration gives a sense of the magnitude of hiring costs or match asset values.

As to the stochastic shocks, in order to get numerical values for the coefficient matrix $\Pi$ and for the variance-co-variance matrix of $\Sigma$ I estimate a first-order VAR in labor productivity growth, the discount factor and the rate of match separation. I estimate this VAR with the relevant data discussed above (see the Appendix for definitions and sources).

\subsection{Model-Data Fit}

I now turn to examine the performance of the model. ${ }^{15}$ Table 6 shows the moments implied by the model and those of the data (repeating the moments reported in Table 4).

\section{Table 6}

The following conclusions can be drawn:

Persistence. The model captures the fact that across all specifications $u, m$ and $s$ are highly persistent. The model tends to somewhat overstate this persistence.

Volatility. Column 1 captures very well the volatility of employment and unemployment. Hiring volatility is understated by the model; best performing is column 0 which captures three quarters of this volatility. As to the labor share, the model overstates its volatility with column

\footnotetext{
${ }^{15}$ I use a modified version of a program by Craig Burnside in Gauss to solve the model [see Burnside (1997)].
} 
(4) being the closest to the data. No single specification produces a high model-data fit for all variables.

Co-Movement. Under most specifications of the model, the counter-cyclical behavior of hiring and the pro-cyclical behavior of the worker hazard rate are well captured. The behavior of the labor share is not captured: while in the data it is a-cyclical to counter-cyclical (across specifications of the unemployment pool) and co-varies moderately with the hiring rate, it is strongly pro-cyclical in the model and has a strong negative relationship with hiring, expect for column 4 where it is positive but overstated.

Overall fit. The model captures the persistence, volatility and some of the co-movement in the data. The major problem concerns the labor share in income which is not well captured. Column 1 of the model fits the data in terms of employment and unemployment behavior and has reasonable but limited success in fitting hiring flows (fits persistence and cyclicality, understates volatility). Column (4) seems to be providing the better fit for the labor share, doing relatively well on volatility, reasonably well on persistence, moderately well on co-movement with hiring and doing badly in terms of cyclical behavior.

The model also generates predictions with respect to the behavior of $v$ and $q$ which are unobserved in U.S. data as explained in sub-section 4.2 above. Strictly speaking the moments involving these variables cannot be compared to the data. But some predictions look reasonable based on the theory and on experience in other economies: the negative correlation of $u$ and $v$ (the 'Beveridge curve') and persistent vacancy rates.

No single specification matches the data on all dimensions. Focusing on the behavior of unemployment, employment and hiring, it looks as though specification 1 (the official unemployment pool and the 'want a job' category) is the most fitting, though specification 0 (official unemployment pool) cannot be ruled out.

I turn now to look at the mechanisms driving this model-data fit.

\section{The Underlying Mechanism}

The discussion up till now has shown which data specification is best explained by the model. The natural question now is what underlies the fit. In order to understand the essential mechanism 
in operation, it is best to consider the following steady-state equation which elaborates on the formulation in (25) and combines it with (26):

$$
\frac{\Theta}{\mu} \widetilde{Q}^{\gamma+1} \frac{\left(\frac{v}{1-u}\right)^{\gamma}}{\left(\frac{v}{u}\right)^{-\sigma}}=\underbrace{\left[\frac{G^{X} \beta}{1-G^{X} \beta(1-\delta)}\right]}_{\Phi} \underbrace{\left[\frac{(1-\eta)\left((1-\alpha)\left[\begin{array}{c}
\frac{1}{1-\alpha \xi} \\
+\Theta\left(\frac{\phi V+(1-\phi) Q V}{N}\right)^{\gamma+1} \frac{\alpha+\gamma}{(1+\gamma)(1-\alpha)(1-\xi(1+\alpha+\gamma))}
\end{array}\right]\right)}{1+\eta P\left[\frac{G^{X} \beta}{1-G^{X} \beta(1-\delta)}\right]}\right]}_{\pi}
$$

where $\widetilde{Q}=\phi+(1-\phi) Q$

Equation (29) shows the vacancy creation decision as an optimality condition equating the marginal costs of hiring with the asset value of the match. The LHS are marginal vacancy creation costs. They take into account $Q$, the probability of filling the vacancy. It is clear that the responsiveness of vacancies $(v)$ depends on the two elasticity parameters $\gamma$ (of the hiring cost function) and $\sigma$ (of the matching function). The higher is each of these, the less responsive is vacancy creation. Many studies have assumed this is a linear function $(\gamma=0)$, thereby imposing a particular shape on the marginal cost function.

The RHS is the asset value of the match. This value can vary because per period profits $\pi$ vary or because the discount factor $\Phi$ varies. The former may vary because of changes in the surplus itself or changes in the sharing of the surplus, with a key parameter being $\eta$. Any policy change in the replacement ratio $\tau$, for example, will change $\eta$ and consequently the sharing of the match surplus. Changes in the discount factor $\Phi$ can happen because of changes in productivity growth $\left(G^{X}\right)$, changes in the discount factor $(\beta)$, or changes in match dissolution rate $(\delta)$.

Hence the essential mechanism is this: changes in the long run (non-stochastic steady state) and in the stochastic dynamics are generated by changes in the surplus, in surplus sharing, in productivity growth, in the discount rate and in the match dissolution rate, that change the match asset values (profitability in present value terms).

The following ingredients are therefore essential:

(i) The shape of the hiring costs function determining the LHS of equation (29) i.e. the 
marginal cost function. In this context $\gamma$ and $\sigma$ are key parameters.

(ii) The formulation of the match surplus - this depends both on the data used and on all key parameters of the model.

(iii) the surplus sharing rule, where $\eta$ is the key parameter.

(iv) the discounting of the match surplus - here the data used (for $G^{X}, \beta$ and $\delta$ ) and their stochastic properties are key.

What is important and what is less important out of these elements of the model? One key element is the convexity of hiring costs, hence there is an important role for $\gamma$. This parameter is important because it is the main determinant of the elasticity of vacancies with respect to the preset value of the match. Values of $\gamma$ thus determine the persistence and volatility of vacancy creation. The latter then influences the second moments of matching, and consequently the moments of unemployment and employment. Another key element is the role played by the match dissolution or separation rate $\delta$. As it is a variable with a relatively high mean it is the main determinant of the relevant discount factor; as it has relatively high volatility and persistence it makes the present value of the match volatile and persistent. This in turn engenders the volatility and persistence of vacancies, hiring and unemployment. Thus the performance of the model hinges to a large extent on the formulation of $\gamma$ and on the stochastic properties of $\delta$. This point is elaborated and reinforced in Yashiv (2005). The lack of fit in part of the literature is due to the use of a linear hiring cost function $(\gamma=0)$ instead of a convex one $(\gamma=2$ here $)$ and due to the incomplete incorporation of the separation rate $\delta$.

Other elements of the model have a smaller role. The wage parameter $\eta$ basically has a scale effect on per period profits and hence on the scale of asset values. It therefore affects the value of the variables at the steady state but does not affect the dynamics, as it does not affect the response of vacancy creation to asset values. The matching function parameter $\sigma$, that does have this 'elasticity' type of affects, has a range of possible variation that is much smaller than the variation in values of $\gamma$. For example, a reasonable change in $\sigma$ would be 0.1 or 0.2 relative to the benchmark value (which is 0.4$)$, but a move from linear $(\gamma=0)$ to cubic $(\gamma=2)$ costs is a change of 2 in the value of $\gamma$. The interest rate and the rate of productivity growth in their turn play a much smaller role than the separation rate in discounting future values. While $\delta$ has a sample mean 
of $8.6 \%$ and a standard deviation of $0.8 \%$, the rate of productivity growth $\left(G^{X}-1\right)$ has a sample mean of $0.4 \%$ and standard deviation of $0.6 \%$ and the rate of interest $\left(\frac{1}{\beta}-1\right)$ has a sample mean of $1.4 \%$ and standard deviation of $5.5 \%$.

The afore-going discussion implies the following modelling lessons for the aggregate U.S. labor market:

(i) In terms of the model formulation, two ingredients are important: convexity of the hiring costs function and allowing separation costs to affect the dynamics, in addition to, and contemporaneously with, any other shock, such as productivity shocks.

(ii) In terms of U.S. data, from amongst the alternative pools of searching workers, the one consisting of official unemployment and the 'want a job' category seems to be the most consistent with the model.

\section{Conclusions}

The paper has formulated a model of the U.S. aggregate labor market using log-linear approximation of the search and matching model. It has looked at alternative formulations of the data that would be consistent with the concepts of the model. Using a VAR of the actual data it injected driving shocks into the model. Comparing the resulting moments implied by the model to the moments in U.S. data, it has shown that it can account for much of observed labor market fluctuations. In particular, the model fits the data on persistence and volatility of most variables, on the negative relationship between vacancies and unemployment, and on the pro-cyclicality of the workers' hazard (job-finding) rate. For the same formulation of the data, it fails to capture the a-cyclicality of the labor share and its moderate positive co-variation with hiring, and it understates the latter's volatility; it is, however, able to come closer to capturing these features given a different configuration of the data.

The analysis has produced an empirically-grounded version of the search and matching model - complete with parameter values and data series - that can be used to study the U.S. labor market, including policy questions.

The paper raises a number of issues for further research. A key one is the need to further explain the mechanisms in operation. In particular, one may ask what is the role of search and 
matching frictions in the dynamics; for example, how would different degrees of frictions lead to different outcomes. This issue is the subject of current research (see Yashiv (2005)). Other issues are: do the results carry over to other economies and, if so, what are the cross-country differences in parameter values and in the dynamics? For example it would be of interest to see whether such differences can explain the different U.S.- European unemployment experiences. 


\section{Data: Sources and Definitions}

Data Sample. All data are quarterly U.S.data for the period 1970:I - 2003:IV, except for hires and separations which begin in 1976:I and end in 2003:III.

Fundamental variables.

\begin{tabular}{|c|c|c|}
\hline variable & symbol & Source \\
\hline Unemployment - official pool & $U^{0}$ & CPS, BLS series id: LNS13000000 \\
\hline Workers out of l.f. who "want a job" & $W A J$ & CPS, BLS series id: LNU05026639 \\
\hline Unemployment - additional pool (see below) & $\widetilde{U}$ & CPS, BLS \\
\hline Employment (total), household survey & $N$ & CPS, BLS series id: LNS12000000 \\
\hline Vacancies - Index of Help Wanted ads & $V$ & Conference Board $^{1}$ \\
\hline Hires & $Q V$ & CPS-based data, Boston Fed computations $^{2}$ \\
\hline Separations & $\delta N$ & CPS-based data, Boston Fed computations $^{2}$ \\
\hline Working age population ${ }^{4}$ & $P O P$ & CPS, BLS series id: LNU00000000 \\
\hline Labor share ${ }^{5}$ & $s=\frac{W N}{F}$ & Table 1.12. NIPA, $\mathrm{BEA}^{3}$ \\
\hline Productivity & $\frac{F}{N}$ & BLS \\
\hline Cost of finance (equity and debt $^{6}$ ) & $\frac{N}{r}$ & Tables 1.1.5; 1.1.6 NIPA, BEA \\
\hline
\end{tabular}

\section{Notes:}

BLS series are taken from http://www.bls.gov/cps/home.htm

1. Data were downloaded from Federal Reserve Bank of St. Louis http://research.stlouisfed.org/fred2/seri

2. See Bleakley et al (1999) for construction methodology. I thank Jeffrey Fuhrer and Elizabeth Walat for their work on this series.

3. http://www.bea.doc.gov/bea/dn/home/gdp.htm

4. Total civilian noninstitutional population 16 years and older.

5. Total compensation of employees divided by GDP. follows:

6. This is a weighted average of the returns to debt, $r_{t}^{b}$, and equity, $r_{t}^{e}$ constructed as

$$
r_{t}=\omega_{t} r_{t}^{b}+\left(1-\omega_{t}\right) r_{t}^{e},
$$

with

$$
\begin{aligned}
r_{t}^{b} & =\left(1-\tau_{t}\right) r_{t}^{C P}-\theta_{t} \\
r_{t}^{e} & =\frac{\widetilde{c f}}{\widetilde{s}_{t}}+\widetilde{\widehat{s}}_{t}-\theta_{t}
\end{aligned}
$$

where:

(i) $\omega_{t}$ is the share of debt finance as reported in Fama and French (1999).

(ii) The definition of $r_{t}^{b}$ reflects the fact that nominal interest payments on debt are tax deductible. $r_{t}^{C P}$ is Moody's seasoned Aaa commercial paper rate. The commercial paper rate for the first month of each quarter represents the entire quarter. The tax rate is $\tau$ as discussed above. 
(iii) $\theta$ denotes inflation and is measured by the GDP-deflator of NFCB GDP.

(iv) For equity return I use the CRSP Value Weighted NYSE, Nasdaq and Amex nominal returns deflated by the inflation rate $\theta$.

The additional pool of unemployment $\widetilde{U}$ has 5 permutations as follows:

\begin{tabular}{|l|l|}
\hline permutation number & $\widetilde{U}$ \\
\hline 0 & 0 \\
\hline 1 & want a job \\
\hline 2 & want a job $+0.15\left(P O P-N-U^{0}\right)$ \\
\hline 3 & want a job $+0.3\left(P O P-N-U^{0}\right)$ \\
\hline 4 & $P O P-N$ \\
\hline
\end{tabular}

Transformations of variables.

\begin{tabular}{|l|l|}
\hline variable & symbol \\
\hline Unemployment - total pool & $U=U^{0}+\widetilde{U}$ \\
\hline Labor force & $L=N+U$ \\
\hline Employment rate & $n=\frac{N}{N+U^{0}+\widetilde{U}}$ \\
\hline Unemployment rate & $u=1-n$ \\
\hline Hiring rate & $m=\frac{Q V}{N}$ \\
\hline Gross rate of labor force growth & $G^{L}=\frac{U_{t+1}+N_{t+1}}{U_{t}+N_{t}}$ \\
\hline Discount factor & $\beta=\frac{1}{1+r}$ \\
\hline
\end{tabular}




\section{References}

[1] Abowd, John and Arnold Zellner, 1985. "Estimating Gross Labor-Force Flows," Journal of Business and Economics Statistics 3, 254-293.

[2] Abraham, Katharine, 1987. "Help-Wanted Advertising, Job Vacancies and Unemployment," Brookings Papers on Economic Activity 1, 207-248.

[3] Abraham, Katharine G. and John C. Haltiwanger, 1995. "Real Wages and the Business Cycle," Journal of Economic Literature 33(3), 1215-64.

[4] Abraham, Katharine G., James R. Spletzer, and Jay C. Stewart, 1999. "Why Do Different Wage Series Tell Different Stories?" American Economic Review , AEA Papers and Proceedings, 89, 2, 34-39.

[5] Anderson, Patricia M. and Bruce D. Meyer, 1997. "Unemployment Insurance Takeup Rates and the After Tax Value of Benefits," Quarterly Journal of Economics CXII, 913-937.

[6] Andolfatto, David, 1996. "Business Cycles and Labor Market Search," American Economic Review 86, 112-132.

[7] Blanchard, Olivier Jean and Peter Diamond, 1989. "The Beveridge Curve," Brookings Papers on Economic Activity 1, 1-60.

[8] Blanchard, Olivier Jean and Peter Diamond, 1990. "The Cyclical Behavior of the Gross Flows of U.S. Workers," Brookings Papers on Economic Activity 2, 85-155.

[9] Bleakley, Hoyt, Ann E. Ferris, and Jeffrey C. Fuhrer 1999. "New Data on Worker Flows During Business Cycles," New England Economic Review July-August, 49-76.

[10] Burdett, Kenneth and Elizabeth J. Cunningham, 1998. " Toward a Theory of Vacancies," Journal of Labor Economics 16(3), 445-78.

[11] Burnside, A. Craig, 1997. "Notes on the Linearization and GMM Estimation of Real Business Cycle Models." mimeo.

[12] Cahuc, Pierre, Francois Marque, and Etienne Wasmer, 2004. "A Theory of Wages and Labor Demand with Intrafirm Bargaining and Matching Frictions," mimeo.

[13] Castillo, Monica D., 1998. "Persons Outside the Labor Force Who Want a Job," Monthly Labor Review, July, 34-42.

[14] Clark, Kim B., and Lawrence H. Summers, 1979. "Labor Market Dynamics and Unemployment: A Reconsideration," Brookings Papers on Economic Activity 1, 13-60.

[15] Cole, Harald L. and Richard Rogerson, 1999. "Can the Mortensen-Pissarides Matching Model Match the Business Cycle Facts?" International Economic Review, 40(4), 933-960.

[16] Diamond, Peter A., 1982. "Wage Determination and Efficiency in Search Equilibrium," Review of Economic Studies 49, 761-782. 
[17] Fallick, Bruce and Charles A. Fleischman, 2004. "Employer to Employer Flows in the U.S. Labor Market: The Complete Picture of Gross Worker Flows," mimeo.

[18] Fama, Eugene F. and Kenneth R. French 1999. "The Corporate Cost of Capital and the Return on Corporate Investment," Journal of Finance LIV:1939-1967.

[19] Fujita, Shigeru, 2004. "Vacancy Persistence," FRB of Philadelphia Working Paper No. 04-23.

[20] Jones, Stephen R.G,.and W.Craig Riddell, 2000. "The Dynamics of U.S. Labor Force Attachment," mimeo.

[21] Krueger, Alan B., 1999. "Measuring Labor's Share," American Economic Review , AEA Papers and Proceedings, 89, 2, 45-51.

[22] Merz, Monika, 1995. "Search in the Labor Market and the Real Business Cycle," Journal of Monetary Economics 36, 269-300.

[23] Merz, Monika and Eran Yashiv, 2004. "Labor and the Market Value of the Firm," CEPR discussion paper no. 4184.

[24] Mortensen, Dale T., 1970."A Theory of Wage and Employment Dynamics," in E.S. Phelps et al (eds.) The Microeconomic Foundations of Employment and Inflation Theory, Norton, New York.

[25] Mortensen, Dale T., 1978. "Specific Capital and Labor Turnover," Bell Journal of Economics $9,572-586$.

[26] Mortensen, Dale T., 1982a. "The Matching Process as a Non-Cooperative Bargaining Game," in J.J. McCall,ed., The Economics of Information and Uncertainty, University of Chicago Press, New York.

[27] Mortensen, Dale T., 1982b. "Property Rights and Efficiency in Mating, Racing and Related Games," American Economic Review 72, 968-79.

[28] Mortensen, Dale T. and Christopher A. Pissarides, 1994. "Job Creation and Job Destruction in the Theory of Unemployment," Review of Economic Studies 61: 397-415.

[29] Mortensen, Dale T. and Christopher A. Pissarides, 1999a. "Job Reallocation, Employment Fluctuations, and Unemployment," Chapter 18 in John B. Taylor and Michael Woodford (eds.), Handbook of Macroeconomics Vol. 1B, 1171-1228, North-Holland, Amsterdam.

[30] Mortensen, Dale T. and Christopher A. Pissarides, 1999b. "New Developments in Models of Search in the Labor Market," Chapter 39 in Orley Ashenfelter and David Card (eds.) Handbook of Labor Economics Vol. 3B, North-Holland, Amsterdam.

[31] Nagypal, Eva, 2004. "Worker Reallocation Over the Business Cycle: The Importance of Job to Job Transitions. Part 1: Evidence," unpublished.

[32] Petrongolo, Barbara and Christopher A. Pissarides, 2001. "Looking Into the Black Box: A Survey of the Matching Function," Journal of Economic Literature, 39 (2), 390-431. 
[33] Pissarides, Christopher A., 1994. "Search Unemployment with On-the-Job Search," Review of Economic Studies 61, 457-475.

[34] Pissarides, Christopher A., 2000. Equilibrium Unemployment Theory, second edition, MIT Press, Cambridge.

[35] Rogerson, Richard, 1997. "Theory Ahead of Language in the Economics of Unemployment," Journal of Economic Perspectives 11,1, 73-92.

[36] Shimer, Robert, 2004. "The Cyclical Behavior of Equilibrium Unemployment and Vacancies: Evidence and Theory," American Economic Review, forthcoming.

[37] Stole, Lars A. and Jeffrey Zwiebel, 1996. "Intrafirm Bargaining under Non-Binding Contracts," Review of Economic Studies, 63, pp. 375-410.

[38] Veracierto, Marcelo, 2002. "On the Cyclical Behavior of Employment, Unemployment and Labor Force Participation," WP 2002-12, Federal Reserve Bank of Chicago.

[39] Yashiv, Eran 2000a. "The Determinants of Equilibrium Unemployment," American Economic Review 90 (5), 1297-1322.

[40] Yashiv, Eran, 2000b. "Hiring as Investment Behavior" Review of Economic Dynamics 3, 486-522.

[41] Yashiv, Eran, 2004. "Macroeconomic Policy Lessons of Labor Market Frictions," European Economic Review, 48, 259-284.

[42] Yashiv, Eran, 2005. "Forward Looking Hiring Behavior and the Dynamics of the Aggregate Labor Market," available at www.tau.ac.il/〜yashiv/ 
Table 1

Stochastic Properties of Alternative Measures

of the Pool of Searching Workers

Quarterly Data

\begin{tabular}{|c|c|c|c|c|c|c|c|}
\hline pool of workers & mean & std. & correlations & & & & \\
\hline & & & 0 & 1 & 2 & 3 & 4 \\
\hline $0=$ official pool $U^{o}$ & 0.06 & 0.014 & 1 & & & & \\
\hline $1=o f f i c i a l+w a n t a j o b$ & 0.10 & 0.020 & 0.976 & 1 & & & \\
\hline $2=$ official + want a job $+0.15\left(P O P-N-U^{0}\right)$ & 0.16 & 0.021 & 0.959 & 0.992 & 1 & & \\
\hline $3=$ official + want a job $+0.3\left(P O P-N-U^{0}\right)$ & 0.21 & 0.021 & 0.937 & 0.977 & 0.996 & 1 & \\
\hline $4=P O P-N$ & 0.39 & 0.022 & 0.856 & 0.908 & 0.953 & 0.977 & 1 \\
\hline
\end{tabular}

\section{Notes:}

1. $P O P$ is working age population; $N$ is civilian employment.

2. See data appendix for sources. 
Table 2

Stochastic Properties of Vacancies and Hires

Quarterly Data

\begin{tabular}{|c|c|c|c|c|c|c|}
\hline & & \multicolumn{2}{|c|}{ individual samples } & \multicolumn{2}{c|}{ common sample } \\
\hline & levels & sample coverage & $\frac{\text { std. }}{\text { mean }}$ & auto-correlation & $\frac{\text { std. }_{\text {mean }}}{\text { auto-correlation }}$ \\
\hline$V$ & help wanted index & $1951: \mathrm{I}-2003: \mathrm{IV}$ & 0.34 & 0.98 & 0.27 & 0.56 \\
\hline$V$ & JOLTS job openings & $2001: \mathrm{I}-2003: \mathrm{IV}$ & 0.24 & 0.61 & 0.24 & 0.61 \\
\hline$Q V$ & hires & $1976: \mathrm{II}-2003: \mathrm{IV}$ & 0.05 & 0.61 & 0.03 & 0.17 \\
\hline & & & & & & \\
\hline & logs, HP-filtered & & std. & auto-correlation & & \\
\hline$V$ & help wanted index & $1951: \mathrm{I}-2003: \mathrm{IV}$ & 0.14 & 0.89 & & \\
\hline$V$ & JOLTS job openings & $2001: \mathrm{I}-2003: \mathrm{IV}$ & 0.28 & 0.60 & & \\
\hline$Q V$ & hires & $1976: \mathrm{II}-2003: \mathrm{IV}$ & 0.03 & 0.05 & & \\
\hline & & & & & & \\
\hline & ratio to unemployment & & $\frac{\text { std. }}{\text { mean }}$ & auto-correlation & std. & auto-correlation \\
\hline$\frac{V}{U}$ & help wanted index & $1951: \mathrm{I}-2003: \mathrm{IV}$ & 0.44 & 0.95 & 0.47 & 0.62 \\
\hline$\frac{V}{U}$ & JOLTS job openings & $2001: \mathrm{I}-2003: \mathrm{IV}$ & 0.35 & 0.66 & 0.35 & 0.66 \\
\hline$\frac{Q V}{U}$ & hires & $1976: \mathrm{II}-2003: \mathrm{IV}$ & 0.16 & 0.94 & 0.15 & 0.64 \\
\hline
\end{tabular}

\section{Note:}

See data appendix for sources. 
Table 3

Worker Hazard Rates $P$

Quarterly 1994-1998

\begin{tabular}{|l|l|l|l|l|}
\hline specification & average & & specification & Jones and Riddell (2000) range \\
\hline 0 & 0.80 & & unemployed & $0.49-0.73$ \\
\hline 1 & 0.82 & & & \\
\hline 2 & 0.47 & & marginally attached & $0.27-0.49$ \\
\hline 3 & 0.39 & & & \\
\hline 4 & 0.14 & & unattached & around 0.10, always below 0.14 \\
\hline
\end{tabular}

\section{Notes:}

1. The five specifications - columns (0) to (4) correspond to the definitions in the notes to Table 1. 
Table 4

Data Properties

\section{a. Sample Means}

\begin{tabular}{|l|c|c|c|c|c|}
\hline & $\mathbf{( 0 )}$ & $\mathbf{( 1 )}$ & $\mathbf{( 2 )}$ & $\mathbf{( 3 )}$ & $\mathbf{( 4 )}$ \\
\hline unemployment rate $u$ & 0.06 & 0.10 & 0.16 & 0.22 & 0.39 \\
\hline hiring rate rate $m=q v$ & 0.046 & 0.079 & 0.074 & 0.070 & 0.054 \\
\hline labor force growth $G^{L}-1$ & 0.0043 & 0.0042 & 0.0041 & 0.0040 & 0.0036 \\
\hline separation rate $\delta$ & 0.040 & \multicolumn{5}{|c|}{0.086} \\
\hline productivity growth $G^{X}-1$ & \multicolumn{5}{|c|}{0.9936} \\
\hline discount factor $\beta$ & \multicolumn{5}{|c|}{0.58} \\
\hline labor share $s$ & \multicolumn{5}{|c|}{} \\
\hline
\end{tabular}

b. Persistence (auto-correlation)

\begin{tabular}{|l|c|c|c|l|l|}
\hline & $\mathbf{( 0 )}$ & $\mathbf{( 1 )}$ & $\mathbf{( 2 )}$ & $\mathbf{( 3 )}$ & $\mathbf{( 4 )}$ \\
\hline$\rho\left(\widehat{u}_{t}, \widehat{u}_{t-1}\right)$ & 0.96 & 0.97 & 0.98 & 0.985 & 0.989 \\
\hline$\rho\left(\widehat{m}_{t}, \widehat{m}_{t-1}\right)$ & 0.91 & 0.85 & 0.84 & 0.84 & 0.81 \\
\hline$\rho\left(\widehat{s}_{t}, \widehat{s}_{t-1}\right)$ & \multicolumn{5}{|c|}{0.88} \\
\hline$\rho\left(\widehat{G}_{t}^{X}, \widehat{G}_{t-1}^{X}\right)$ & \multicolumn{5}{|c|}{-0.014} \\
\hline$\rho\left(\widehat{\delta}_{t}, \widehat{\delta}_{t-1}\right)$ & 0.92 & \multicolumn{5}{|c|}{0.89} \\
\hline$\rho\left(\widehat{\beta}_{t}, \widehat{\beta}_{t-1}\right)$ & \multicolumn{5}{|c|}{0.02} \\
\hline
\end{tabular}

c. Volatility (standard deviation)

\begin{tabular}{|l|c|c|c|c|c|}
\hline & $(\mathbf{0})$ & $\mathbf{( 1 )}$ & $\mathbf{( 2 )}$ & $\mathbf{( 3 )}$ & $\mathbf{( 4 )}$ \\
\hline$\widehat{n}$ & 0.015 & 0.022 & 0.024 & 0.028 & 0.042 \\
\hline$\widehat{u}$ & 0.22 & 0.19 & 0.12 & 0.10 & 0.07 \\
\hline$\widehat{m}$ & 0.13 & 0.09 & 0.08 & 0.08 & 0.07 \\
\hline$\frac{m}{u}$ & 0.12 & 0.14 & 0.07 & 0.05 & 0.04 \\
\hline$\widehat{s}$ & \multicolumn{5}{|c|}{0.016} \\
\hline$\widehat{G}^{X}$ & \multicolumn{5}{|c|}{0.007} \\
\hline$\widehat{\delta}$ & 0.16 & \multicolumn{5}{|c|}{0.06} \\
\hline$\widehat{\beta}$ & \multicolumn{6}{|c|}{} \\
\hline
\end{tabular}




\section{d. Co-movement (correlation)}

\begin{tabular}{|l|c|c|c|c|c|}
\hline & $\mathbf{( 0 )}$ & $\mathbf{( 1 )}$ & $\mathbf{( 2 )}$ & $\mathbf{( 3 )}$ & $\mathbf{( 4 )}$ \\
\hline$\rho\left(\widehat{u}_{t}, \widehat{m}_{t}\right)$ & 0.92 & 0.81 & 0.86 & 0.88 & 0.87 \\
\hline$\rho\left(\widehat{u}_{t}, \widehat{P}_{t}\right)$ & -0.91 & -0.93 & -0.80 & -0.59 & 0.24 \\
\hline$\rho\left(\widehat{n}_{t}, \widehat{s}_{t}\right)$ & -0.06 & -0.16 & -0.30 & -0.39 & -0.52 \\
\hline$\rho\left(\widehat{m}_{t}, \widehat{s}_{t}\right)$ & 0.27 & 0.45 & 0.45 & 0.44 & 0.41 \\
\hline$\rho\left(\widehat{n}_{t}, \widehat{G}_{t}^{X}\right)$ & -0.10 & -0.03 & 0.001 & 0.02 & 0.06 \\
\hline$\rho\left(\widehat{n}_{t}, \widehat{\beta}_{t}\right)$ & 0.15 & 0.10 & 0.04 & 0.00 & -0.08 \\
\hline$\rho\left(\widehat{n}_{t}, \widehat{\delta}_{t}\right)$ & -0.93 & -0.88 & -0.91 & -0.92 & -0.91 \\
\hline
\end{tabular}

\section{Notes:}

1. All data are quarterly for the period 1970:I - 2003:IV, except for hires and separations which begin in 1976:I and end in 2003:III.

2. The different columns differ with respect to the specification of the unemployment pool. I defiine $U=U^{0}+\widetilde{U}$ and $L=N+U$ where $U^{0}$ is the official pool and $\widetilde{U}$ are the following additions: Column 1 adds workers out of the labor force indicating that they "want a job." Columns 2 and 3 add to the latter column $15 \%$ and $30 \%$ of the remaining persons out of the labor force. Column 4 considers the entire working age population as the labor force. Column 0 is the official unemployment pool. 
Table 5

Baseline Calibration Values

a. Parameters, Exogenous Variables and Steady State Values

\begin{tabular}{|l|l|l|l|l|l|l|}
\hline Parameter/Variable & symbol & $\mathbf{( 0 )}$ & $\mathbf{( 1 )}$ & $\mathbf{( 2 )}$ & $\mathbf{( 3 )}$ & $\mathbf{( 4 )}$ \\
\hline Production & $1-\alpha$ & \multicolumn{5}{|c|}{0.68} \\
\hline Matching & $\sigma$ & \multicolumn{5}{|c|}{0.4} \\
\hline Hiring & $\gamma$ & \multicolumn{5}{|c|}{0.3} \\
\hline Hiring II & $\phi$ & \multicolumn{5}{|c|}{0.003536} \\
\hline \hline productivity growth & $G^{X}-1$ & \multicolumn{5}{|c|}{0.9929} \\
\hline labor force growth & $G^{L}-1$ & 0.004296 & 0.004199 & 0.004078 & 0.003974 & 0.003631 \\
\hline discount factor & $\beta$ & & \multicolumn{5}{|c|}{0.0854} & 0.395 \\
\hline separation rate & $\delta$ & 0.0404 & \multicolumn{5}{|c|}{0.579} & 0.217 & 0.395 \\
\hline \hline Unemployment & $u$ & 0.063 & 0.104 & 0.164 & 0.9 \\
\hline Labor share & $s$ & \multicolumn{5}{|c|}{} \\
\hline Vacancy matching rate & $Q$ & \multicolumn{5}{|c|}{0.5} \\
\hline
\end{tabular}

\section{b. Implied Values}

\begin{tabular}{|l|c|c|c|c|c|c|}
\hline & & $\mathbf{( 0 )}$ & $\mathbf{( 1 )}$ & $\mathbf{( 2 )}$ & $\mathbf{( 3 )}$ & $\mathbf{( 4 )}$ \\
\hline Matching & $\mu$ & 0.80 & 0.85 & 0.69 & 0.60 & 0.42 \\
\hline Hiring & $\Theta$ & 465 & 82 & 109 & 127 & 171 \\
\hline Wage bargaining parameter & $\xi$ & 0.37 & 0.41 & 0.45 & 0.49 & 0.56 \\
\hline Wage parameter & $\eta$ & 0.44 & 0.48 & 0.53 & 0.56 & 0.63 \\
\hline \hline Vacancy rate & $v$ & 0.047 & 0.089 & 0.083 & 0.078 & 0.060 \\
\hline Market tightness & $\frac{v}{u}$ & 0.74 & 0.86 & 0.51 & 0.36 & 0.15 \\
\hline Workers' hazard & $P$ & 0.67 & 0.77 & 0.46 & 0.32 & 0.14 \\
\hline Profits & $\pi$ & 0.05 & 0.07 & 0.09 & 0.10 & 0.13 \\
\hline Asset Value & $\lambda$ & 1.02 & 0.73 & 0.96 & 1.12 & 1.49 \\
\hline
\end{tabular}

\section{Notes:}

1. The implied values of $v, \mu, \Theta$ and $\eta$ are solved for using the steady state relationships as follows:

Matching hazard:

$$
Q=\mu\left(\frac{v}{u}\right)^{-\sigma}
$$

Beveridge curve:

$$
\left(\delta+G^{L}-1\right)=\mu\left(\frac{v}{u}\right)^{-\sigma}\left(\frac{v}{1-u}\right)
$$




\section{Vacancy creation:}

$$
\Theta(\phi+(1-\phi) Q)\left(\frac{\phi V+(1-\phi) Q V}{N}\right)^{\gamma}=Q \frac{G^{X} \beta}{\left[1-(1-\delta) G^{X} \beta\right]} \pi
$$

\section{Wage solution}

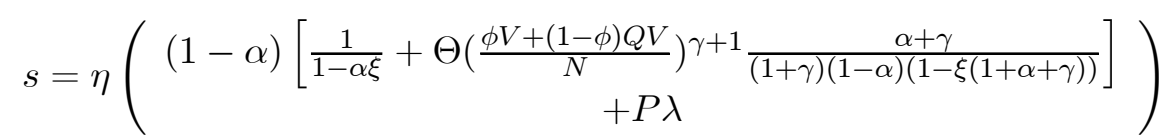

The other variables are solved for using:

$$
\begin{aligned}
P & =\frac{Q v}{u} \\
\pi & =\frac{(1-\eta)\left((1-\alpha)\left[+\Theta\left(\frac{\phi V+(1-\phi) Q V}{N}\right)^{\gamma+1} \frac{\frac{1}{1-\alpha \xi}(1+\gamma)(1-\alpha)(1-\xi(1+\alpha+\gamma))}{(1-\alpha)}\right]\right)}{1+\eta P \frac{G^{X} \beta}{\left[1-(1-\delta) G^{X} \beta\right]}} \\
\lambda & =\frac{G^{X} \beta}{\left[1-(1-\delta) G^{X} \beta\right]} \pi
\end{aligned}
$$

2. The five specifications - columns (0) to (4) correspond to the definitions in the notes to Table 4 . 
Table 6

Model Evaluation: Alternative Specifications

a. Model vs. Data

\begin{tabular}{|l|l|l|l|l|l|l|}
\hline & & $\mathbf{( 0 )}$ & $\mathbf{( 1 )}$ & $\mathbf{( 2 )}$ & $\mathbf{( 3 )}$ & $\mathbf{( 4 )}$ \\
\hline \hline$\rho\left(\widehat{u}_{t}, \widehat{u}_{t-1}\right)$ & Data & 0.962 & 0.971 & 0.980 & 0.985 & 0.989 \\
\hline & Model & 0.989 & 0.983 & 0.990 & 0.993 & 0.996 \\
\hline \hline$\rho\left(\widehat{m}_{t}, \widehat{m}_{t-1}\right)$ & Data & 0.907 & 0.853 & 0.844 & 0.836 & 0.805 \\
\hline & Model & 0.991 & 0.986 & 0.991 & 0.993 & 0.992 \\
\hline \hline$\rho\left(\widehat{s}_{t}, \widehat{s}_{t-1}\right)$ & Data & 0.884 & 0.884 & 0.884 & 0.884 & 0.884 \\
\hline & Model & 0.982 & 0.976 & 0.988 & 0.992 & 0.996 \\
\hline \hline$s t d\left(\widehat{n}_{t}\right)$ & Data & 0.015 & 0.022 & 0.024 & 0.028 & 0.042 \\
\hline & Model & 0.020 & 0.021 & 0.032 & 0.042 & 0.072 \\
\hline \hline$s t d\left(\widehat{u}_{t}\right)$ & Data & 0.218 & 0.188 & 0.124 & 0.100 & 0.069 \\
\hline & Model & 0.298 & 0.182 & 0.165 & 0.151 & 0.110 \\
\hline \hline$s t d\left(\widehat{m}_{t}\right)$ & Data & 0.125 & 0.085 & 0.083 & 0.080 & 0.073 \\
\hline & Model & 0.097 & 0.051 & 0.035 & 0.022 & 0.018 \\
\hline \hline$s t d\left(\widehat{s}_{t}\right)$ & Data & 0.016 & 0.016 & 0.016 & 0.016 & 0.016 \\
\hline & Model & 0.089 & 0.056 & 0.052 & 0.049 & 0.038 \\
\hline \hline$\rho\left(\widehat{u}_{t}, \widehat{m}_{t}\right)$ & Data & 0.920 & 0.810 & 0.860 & 0.880 & 0.870 \\
\hline & Model & 0.997 & 0.997 & 0.998 & 0.999 & -0.982 \\
\hline \hline$\rho\left(\widehat{u}_{t}, \widehat{P}_{t}\right)$ & Data & -0.909 & -0.933 & -0.802 & -0.591 & 0.242 \\
\hline & Model & -0.999 & -1.000 & -1.000 & -1.000 & -1.000 \\
\hline \hline$\rho\left(\widehat{n}_{t}, \widehat{s}_{t}\right)$ & Data & -0.060 & -0.160 & -0.300 & -0.390 & -0.520 \\
\hline & Model & 0.995 & 0.997 & 0.999 & 1.000 & 1.000 \\
\hline \hline$\rho\left(\widehat{m}_{t}, \widehat{s}_{t}\right)$ & Data & 0.272 & 0.451 & 0.445 & 0.440 & 0.414 \\
\hline & Model & -0.985 & -0.989 & -0.996 & -0.999 & 0.984 \\
\hline & & & & &
\end{tabular}

b. Model predictions

\begin{tabular}{|l|l|l|l|l|l|}
\hline & $\mathbf{( 0 )}$ & $\mathbf{( 1 )}$ & $\mathbf{( 2 )}$ & $\mathbf{( 3 )}$ & $\mathbf{( 4 )}$ \\
\hline \hline$\rho\left(\widehat{v}_{t}, \widehat{v}_{t-1}\right)$ & 0.952 & 0.961 & 0.986 & 0.992 & 0.996 \\
\hline$\rho\left(\widehat{q}_{t}, \widehat{q}_{t-1}\right)$ & 0.988 & 0.981 & 0.989 & 0.992 & 0.996 \\
\hline$s t d\left(\widehat{v}_{t}\right)$ & 0.040 & 0.037 & 0.052 & 0.064 & 0.103 \\
\hline$s t d\left(\widehat{q}_{t}\right)$ & 0.135 & 0.088 & 0.087 & 0.086 & 0.085 \\
\hline$\rho\left(\widehat{u}_{t}, \widehat{v}_{t}\right)$ & -0.956 & -0.985 & -0.998 & -1.000 & -0.999 \\
\hline$\rho\left(\widehat{v}_{t}, \widehat{q}_{t}\right)$ & -0.966 & -0.990 & -0.999 & -1.000 & -1.000 \\
\hline$\rho\left(\widehat{v}_{t}, \widehat{s}_{t}\right)$ & 0.981 & 0.995 & 0.999 & 1.000 & 0.999 \\
\hline
\end{tabular}

Notes:

The different specifications correspond to the definitions in Table 4. 


\section{CENTRE FOR ECONOMIC PERFORMANCE Recent Discussion Papers}

676 Alex Bryson

Rafael Gomez

Tobias Kretschmer

675 Nick Bloom Mark Schankerman

John Van Reenen

674 Lorraine Dearden

Howard Reed

John Van Reenen

673 Giulia Faggio

Stephen Nickell

672 Chiara Criscuolo

Ralf Martin

671 Roberto Torrini

670 Silvia Ardagna

Francesco Caselli

Timothy Lane

669 Alejandro Cuñat

Marco Maffezzoli

668 Francesco Caselli

Silvana Tenreyro

667 Francesco Caselli

666 Gianluca Benigno

Pierpaolo Benigno

665 Olmo Silva
Catching a Wave: the Adoption of Voice and High Commitment Workplace Practices in Britain: 19841998

Identifying Technology Spillovers and Product Market Rivalry

The Impact of Training on Productivity and Wages: Evidence from British Panel Data

Inactivity Among Prime Age Men in the UK

Multinationals and US Productivity Leadership:

Evidence from Great Britain

Profit Share and Returns on Capital Stock in Italy: the Role of Privatisations Behind the Rise of the 1990s

Fiscal Discipline and the Cost of Public Debt Service: Some Estimates for OECD Countries

Can Comparative Advantage Explain the Growth of US Trade?

Is Poland the Next Spain?

Accounting for Cross-Country Income Differences

Designing Target Rules for International Monetary Policy Cooperation

Entrepreneurship: Can the Jack-of-All-Trades Attitude be Acquired? 
664 Maarten Goos

663 Christopher A. Pissarides Giovanna Vallanti

662 Philip R. Lane Gian Maria Milesi-Ferretti

661
Alex Bryson
Lorenzo Cappellari
Claudio Lucifora

660 David Marsden

Richard Belfield

659 Rachel Griffith

Rupert Harrison

John Van Reenen

658 Douglas Kruse

Richard B. Freeman

Joseph Blasi

Robert Buchele

Adria Scharf

Loren Rodgers

Chris Mackin

657 Christopher Crowe

656 James Banks

Richard Disney

Alan Duncan

John Van Reenen

655 Eran Yashiv

654 Hilary Steedman

Sheila Stoney
Sinking the Blues: the Impact of Shop Closing Hours on Labor and Product Markets

Productivity Growth and Employment: Theory and Panel Estimates

Financial Globalization and Exchange Rates

Do Job Security Guarantees Work?

Unions, Performance-Related Pay and Procedural

Justice: the Case of Classroom Teachers

How Special is the Special Relationship? Using the Impact of R\&D Spillovers on UK Firms As a Test of Technology Sourcing

Motivating Employee Owners in ESOP Firms:

Human Resource Policies and Company Performance
Inflation, Inequality and Social Conflict

The Internationalisation of Public Welfare Policy

The Centre for Economic Performance Publications Unit Tel 02079557673 Fax 02079557595 Email info@cep.lse.ac.uk Web site http://cep.lse.ac.uk 